\title{
RELACIÓN DE LA EXPRESIÓN DE LOS GENES DE SÍNTESIS Y SEÑALIZACIÓN DE MELATONINA EN EL CÁNCER COLORRECTAL CON EL ESTATUS DE P53.
}
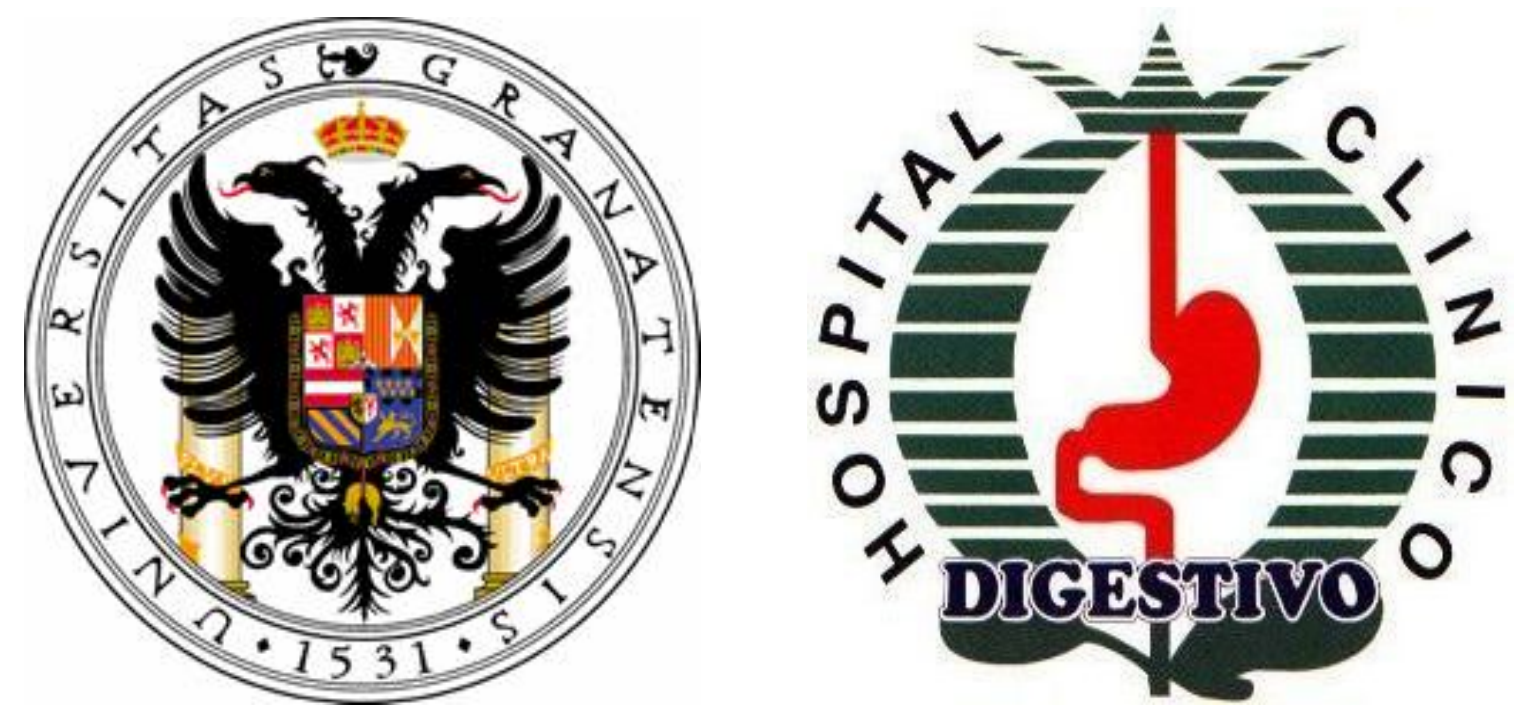

TRABAJO FIN DE MASTER

AVANCES EN RADIOLOGÍA DIAGNÓSTICA Y TERAPÉUTICA Y MEDICINA FÍSICA

Almudena María Íñigo Chaves

Julio 2014

Directores: Josefa León López 
A mi Jefe y los compañeros de investigación.

Sabemos los que somos, pero aún no sabemos lo que podemos llegar a ser.

William Shakespeare 
1. CÁNCER COLORRECTAL (CCR) 5

1.1 Factores de riesgo de cáncer colorrectal 5

1.1.1 Predisposición genética 6

$\begin{array}{lll}\text { 1.1.2 Factores ambientales } & 6\end{array}$

$\begin{array}{ll}1.2 \text { Clínica del cáncer colorrectal } & 7\end{array}$

1.3 Screening del cáncer colorrectal 8

1.4 Diagnóstico del cáncer colorrectal 8

$\begin{array}{ll}1.5 \text { Tratamiento del cáncer colorrectal } & 9\end{array}$

2 P53 GENERALIDADES Y SU RELACIÓN CON EL CCR 9

$\begin{array}{ll}2.1 \text { Estructura de } \mathrm{p} 53 & 12\end{array}$

$\begin{array}{ll}2.2 \text { P53 y microRNAs } & 13\end{array}$

$\begin{array}{ll}2.3 \text { P53 y cáncer colorrectal } & 14\end{array}$

3 MELATONINA 16

3.1 Síntesis y regulación de la melatonina $\quad 16$

$\begin{array}{ll}3.2 \text { Receptores de melatonina } & 17\end{array}$

$\begin{array}{ll}3.3 \text { Melatonina y tracto gastrointestinal } & 18\end{array}$

$\begin{array}{ll}3.4 \text { Melatonina y cáncer } & 19\end{array}$

3.5 Melatonina y cáncer colorrectal 20

$\begin{array}{ll}3.6 \text { Melatonina y } 553 & 21\end{array}$

HIPÓTESIS Y OBJETIVOS 22

\section{MATERIALES Y MÉTODOS}

1. Cultivos celulares 23

2. Pacientes 23

3. Extracción de ARN 24

4. Síntesis de ADNc 25

5. PCR a tiempo real 25

6. Extracción de ADN 26

7. Determinación de mutaciones de p53 27

7.1. Extracción ADN 27

7.2. Amplificacion $\mathrm{ADN}$ con primers que flanquean los exones en regiones $\begin{array}{ll}\text { intrónicas. } & 27 \\ & \end{array}$

7.3. Secuenciación de los exones 29

7.4. Interpretación del cromatograma 29

8. Análisis estadístico $\quad 30$ 
1. Caracterización de las mutaciones de $\mathrm{p} 53$

2. Relación del estatus del gen TP53 con la expresión de los genes NAT, ASMT, MT1, MT2 y ROR $\alpha$

3. Análisis de la expresión de NAT, ASMT, MT1, MT2 Y ROR $\alpha$ en líneas celulares establecidas de cáncer de colon 


\section{INTRODUCCIÓN}

\section{CÁNCER COLORRECTAL}

El cáncer colorrectal (CCR) es el tercer cáncer más común en el mundo, diagnosticándose cerca de 1.4 millones de casos nuevos en 2012 (Fuente: World Cancer Research Fund International; extraído de: wcrf.org/cancer_statistics/index.php). Es el tercer cáncer más común en hombres y el segundo en mujeres en todo el mundo (International Agency for Research on Cancer; Globocan 2012: Estimated Cancer Incidence, Mortality and Prevalence Worldwide in 2012; extraído de: http://globocan.iarc.fr/)

La prevalencia en España es de 60.42 casos por año por cada 100.000 habitantes. En concreto, en Granada, en el periodo 2007-2009, la incidencia media anual de cáncer de colon presentó unas tasas brutas de 41 y 41 por 100.000 hombres y mujeres, respectivamente. La tasa bruta de mortalidad media anual en el periodo 2003-2007 fue de 28 y 20 por 100.000 hombres y mujeres respectivamente (Registro de 'Cáncer de Granada; extraído de: cancergranada.org/es/index.cfm)

Las tasas de mortalidad han ido disminuyendo a los largo de los años. Esto es debido tanto a la detección precoz de lesiones precancerosas gracias a los programas de screening, como a tratamientos más efectivos (Lee y Sonnenberg, 2013).

$\mathrm{Su}$ desarrollo es lento, en un periodo de 10 a 20 años. La mayoría comienzan como pólipos, siendo los más comunes los llamados adenomatosos o adenomas. Aunque todos los adenomas tienen la capacidad de malignizar, menos de un $10 \%$ progresa a un carcinoma invasivo (Risio, 2010). Los cánceres que se desarrollan de las células glandulares se llaman adenocarcinomas; la mayoría de los CCR (aproximadamente 96\%) son adenocarcinomas (Stewart y cols., 2006).

\subsection{Factores de riesgo para el CCR}

Podemos afirmar que el CCR y la alta incidencia que lo acompaña son debidos tanto a factores genéticos como ambientales (dieta rica en grasas, carnes rojas y procesadas, sendentarismo, obesidad, ingesta de alcohol, entre otros) (Tabla 1) (Colorectal Cancer Facts and Figures 2014- 2016, American Cancer Society).

Las tasas de incidencia y mortalidad aumentan con la edad. El 90\% de los casos de diagnostican después de los 50 años. El sexo es otro factor de riesgo, siendo más frecuente en hombres que en mujeres, esto podría explicarse por complejas interacciones hormonales en los distintos sexos (Murphy y cols., 2011). La mayoría de los CCR son esporádicos, aunque se encuentra un aumento de incidencia en los familiares de pacientes diagnosticados, lo que nos hace pensar en la participación de factores hereditarios (Weitz y cols., 2005). 


\subsubsection{Predisposición genética}

El modo de presentación del CCR puede seguir tres patrones: esporádico, familiar o hereditario. La forma esporádica cuenta con el 70\% de los CCR, menos del 10\% se deben a predisposición genética y estos a su vez se dividen en función de la aparición de pólipos o no. Por último un $25 \%$ es el llamado CCR familiar; los individuos pertenecientes a estas familias tienen un aumento del riesgo de CCR, aunque el riesgo en estos casos no es tan alto como en los síndromes hereditarios. Existen dos tipos de CCR hereditario: el Síndrome de Lynch o cáncer de colon hereditario no polipósico (CCHNP) y la Poliposis adenomatosa familiar (Bogaert y Prenen, 2014).

El síndrome de Lynch es la forma más común de CCR herediatario. Es una enfermedad autosómica dominante con alta penetrancia (cercana al 80\%) responsable del aproximadamente el 3\% de todos los adenocarcinomas colónicos (Bonis y cols., 2007). Suele aparecer en individuos jóvenes y con una predominancia (alrededor del $70 \%$ ) en el colon derecho.

La inactivación de una serie de genes (MSH 2, MSH 6, MLH 1, MLH 3, PMS1 Y PMS2), produce la acumulación de una serie de mutaciones en el genoma que se conoce como inestabilidad de los microsatélites. Casi todos los afectados por el síndrome tienen altos niveles de inestabilidad de los microsatelites, hecho que también aparece en el 15\% de los cánceres de colon esporádicos.

La Poliposis adenomatosa familiar es el segundo síndrome genético que predispone a CCR más frecuente. Se caracteriza por la aparición de cientos a miles de pólipos en los individuos afectados (Jasperson y cols., 2010). Es una enfermedad autosómica dominante causada por mutaciones en el gen APC, localizado en el cromosoma 5q21-q22.

El riesgo de desarrollar un CCR en estos individuos en el $100 \%$, siendo la edad media de aparición los 39 años.

\subsubsection{Factores ambientales}

Las diferencias geográficas en las tasas de CCR y el aumento del riesgo en la población inmigrante hace pensar que tanto la dieta como el estilo de vida tiene una gran influencia en la aparición de esta patología.

El alto consumo de carnes rojas y procesadas, la ingesta de alcohol y el consumo de tabaco, la obesidad y la vida sedentaria son factores de riesgo.

Existe evidencia de que, el uso de aspirina (así como de otros AINES) a largo plazo y de forma regular reduce el riesgo de CCR (Rothwell y cols., 2010); aunque la Sociedad Americana del Cáncer no recomienda su uso en la población general por sus potenciales reacciones adversas gastrointestinales.

Se ha hablado también de menor tasa de CCR en mujeres postmenopáusicas en tratamiento hormonal sustitutivo (THS) (Rossouw y cols., 2002), aunque el riesgo se igualaría de nuevo a las no consumidoras de THS pasados los tres años de cese de tratamiento (Heiss y cols., 2008). 


\begin{tabular}{|c|c|}
\hline & Riesgo Relativo* \\
\hline \multicolumn{2}{|l|}{ Factores que aumentan el riesgo: } \\
\hline \multicolumn{2}{|l|}{ Herencia e historia clínica } \\
\hline \multicolumn{2}{|l|}{ Historia familiar } \\
\hline Familiar de primer grado & 2.2 \\
\hline Más de un familiar & 4.0 \\
\hline Familiar con diagnóstico antes de los 45 & 3.9 \\
\hline \multicolumn{2}{|l|}{ Enfermedad inflamatoria intestinal } \\
\hline Enfermedad de Crohn (colon) & 2.6 \\
\hline \multicolumn{2}{|l|}{ Colitis ulcerosa } \\
\hline Colon & 2.8 \\
\hline Recto & 1.2 \\
\hline Diabetes & 1.2 \\
\hline \multicolumn{2}{|l|}{ Hábitos personales } \\
\hline Consumo de alcohol & 1.6 \\
\hline Obesidad & 1.2 \\
\hline Consumo de carne roja & 1.2 \\
\hline Consumo de carnes procesadas & 1.2 \\
\hline Tabaco & 1.2 \\
\hline \multicolumn{2}{|l|}{ Factores que disminuyen el riesgo } \\
\hline Actividad física (colon) & 0.7 \\
\hline Consumo diario & 0.8 \\
\hline Consumo de fruta & 0.9 \\
\hline Consumo de verduras & 0.9 \\
\hline Fibra total en la dieta (10g/día) & 0.9 \\
\hline \multicolumn{2}{|c|}{$\begin{array}{l}\text { *El riesgo relativo compara el riesgo entre personas con una exposición concreta con personas sin es } \\
\text { exposición. El riesgo relativo para los factores dietéticos compara el mayor consumo con el meno } \\
\text { consumo. Si el riesgo relativo es mayor de } 1.0 \text {, el riesgo es mayor en expuestos que en no expuestos. Ui } \\
\text { riesgo relativo menor de } 1.0 \text { indica efecto protector. }\end{array}$} \\
\hline
\end{tabular}

*Extraído de Colorectal Cancer Facts and Figures 2014-2016. American Cancer Society.

\subsection{Clínica del CCR.}

En estadios iniciales del CCR no suelen aparecer síntomas y los pacientes que son diagnosticados es gracias a los programas de screening. Sin embargo, a pesar del aumento del número de pacientes diagnosticados en fases iniciales gracias a programas de cribado, muchos CCR se diagnostican una vez el paciente comienza a tener síntomas (Speights y cols., 1991).

Los signos y síntomas incluyen hemorragia oculta que puede causar anemia ferropénica, dolor abdominal y cambios en el hábito intestinal, astenia y pérdida de peso entre otros (Speights y cols., 1991). 


\subsection{Screening del CCR}

El lento crecimiento desde una lesión precancerosa, en este caso un pólipo colónico, hasta un cáncer invasivo, nos da una oportunidad única de prevención y detección temprana del CCR (Winawer y Zauber, 2002).

Según los grupos de riesgo, The American College of Gastroenterology propone las siguientes recomendaciones para el screening (Douglas y cols., 2009).

- En caso de no existir historia familiar de CCR ni antecedentes personales el screening comenzaría a los 50 años -evidencia 1B- (en caso de Afroamericanos a los 45 años -evidencia 2C-). En estos casos se realizaría test de sangre oculta (TSOH) anualmente, análisis de $\mathrm{ADN}$ en heces cada 3 años; aunque lo más recomendado sería la colonoscopia cada 10 años o la sigmoidoscopia flexible cada 5-10 años. En estas recomendaciones se incluye la colonoscopia por TC cada 5 años.

- Personas con un solo familiar de primer grado diagnosticado de CCR o adenomas con displasia de alto grado después de los 60 años seguirán las mismas recomendaciones que las personas con bajo riesgo.

- Personas con un familiar de primer grado con CCR o adenomas de alto grado diagnosticados antes de los 60 años, o bien dos o más familiares de primer grado con CCR o adenomas de alto grado, comenzarán el programa de despistaje con 40 años o 10 años antes de la edad del familiar más joven diagnosticado. En estos casos se recomienda realizar colonoscopia cada 5 años.

- Pacientes con poliposis adenomatosa familiar (PAF) (> 100 pólipos) deberían beneficiarse de consejo genético y realizarse test genéticos si tienen hermanos o hijos que podrían beneficiarse de estos test.

- Pacientes con PAF conocida o con historia familiar (y sin test genéticos) deberán someterse anualmente a sigmoidoscopia flexible o colonoscopia comenzando a los 10-12 años.

- Los pacientes que reúnan los criterios de Bethesda para el síndrome de Lynch o CCHNP deben comprobar la inestabilidad de los microsatélites del tumor. Aquellos familiares de pacientes diagnosticados de CCHNP o aquellos pacientes con test genéticos positivos deben realizarse una colonoscopia cada 2 años comenzando a los 20-25 años hasta los 40 años, a partir de entonces anualmente.

\subsection{Diagnóstico del CCR}

El CCR puede ser diagnosticado en estadios iniciales gracias a los programas de cribado o bien diagnosticarlo por la sintomatología del paciente. De este modo el cáncer en colon derecho suele presentarse habitualmente con astenia, pérdida de peso y anemia ferropénica, mientras que el cáncer en colon izquierdo es más dado a causar dolor abdominal o signos de obstrucción en estadios más avanzados (Hamilton y cols., 2005).

De todas las técnicas utilizadas para el diagnóstico del CCR la de elección es la colonoscopia. Con una sensibilidad del $90-95 \%$ y un índice de complicaciones en tornos 
al 2\% en las terapéuticas; puede localizar lesiones y tomar biopsias, detectar tumores sincrónicos o quitar pólipos (Rockey y cols., 2005).

El enema opaco y con bario es poco utilizado, tanto por la alta disponibilidad de la colonoscopia, como por su menor sensibilidad y por no poder realizarse técnicas terapéuticas (Halligan y cols., 2013).

La colonoscopia virtual proporciona una perspectiva del colon simulada por ordenador. Es menos invasiva que otras técnicas y no necesita un tiempo de recuperación, sin embargo, ante el hallazgo de pólipos u otros resultados anormales los pacientes deberán realizarse una colonoscopia (Johnson y cols., 2008).

\subsection{Tratamiento del CCR}

El primer tratamiento a considerar es la resección quirúrgica, si bien la situación de cada paciente es estudiada de manera individual y el tratamiento se hará en función de la extensión del tumor y el estado general del paciente.

En estadios localizados, sin evidencia de extensión del tumor a ganglios linfáticos u órganos adyacentes el tratamiento principal es la resección quirúrgica del segmento afectado. En estadios más avanzados, con crecimiento del tumor a otros tejidos, o evidencia de células tumorales en los bordes de la pieza de resección se recomienda el tratamiento con radioterapia y/o quimioterapia adyuvante (Colorectal Cancer Facts and Figures 2014- 2016).

Ante la aparición de metástasis, la quimioterapia, radioterapia y las terapias biológicas pueden ser de ayuda para aliviar los síntomas y prologar la supervivencia. Se han propuesto una serie de fármacos aprobados por la FDA, como los VEGF o los EGFR (Wang y cols., 2010).

Las metástasis hepáticas son muy frecuentes en el cáncer de colon. Si el hallazgo es de una lesión aislada, existe la posibilidad de resección de en cuña con un margen. Si por el contrario las características de la lesión (número, tamaño o localización) requieren la realización de una hepatectomía, ésta podría realizarse en un segundo tiempo (Wu y cols., 2011).

\section{P53: GENERALIDADES Y SU RELACIÓN CON EL CCR}

En las últimas tres décadas, estudios moleculares genéticos revelan mutaciones subyacentes en la patogénesis del CCR, tanto en su forma esporádica como en las formas hereditarias. Un número relativamente limitado de oncogenes y genes supresores de tumores (más frecuentemente gen APC, gen KRAS y gen p53) están mutados en un considerable número de cánceres colorrectales, y una cantidad aún más considerable, que también están mutados están empezando a definirse. Esto, junto con la metilación del ADN y los cambios en la estructura de la cromatina, desajustan los sistemas de señalización, que ejercen efectos dependientes del contexto en ciertos fenotipos celulares, incluyendo la regulación del metabolismo celular, proliferación, diferenciación y supervivencia. Parece necesario continuar con los estudios sobre este 
tema para comprender completamente la naturaleza y el significado de los defectos genéticos y epigenéticos, tanto individuales como colectivos, en relación al CCR (Fearon, 2011).

El gen supresor de tumores TP53, localizado en el cromosoma 17p13.1 es conocido como el 'guardián del genoma'. Este gen contiene 11 exones y transcribe un mRNA de $2.8 \mathrm{~kb}$. P53, una fosfoproteína de 393 aminoácidos, actúa como un regulador del crecimiento celular y juega un papel fundamental en respuesta a diversas señales de estrés o daño celular, en la inducción de ciertos genes que son importantes en la detención del ciclo celular y la apoptosis que sigue al daño en el ADN (Figura 1); de esta manera inhibe la proliferación de células tumorales. Por tanto, un TP53 funcionalmente normal es esencial para proteger al organismo del desarrollo de tumores (Naccarati, y cols., 2011).

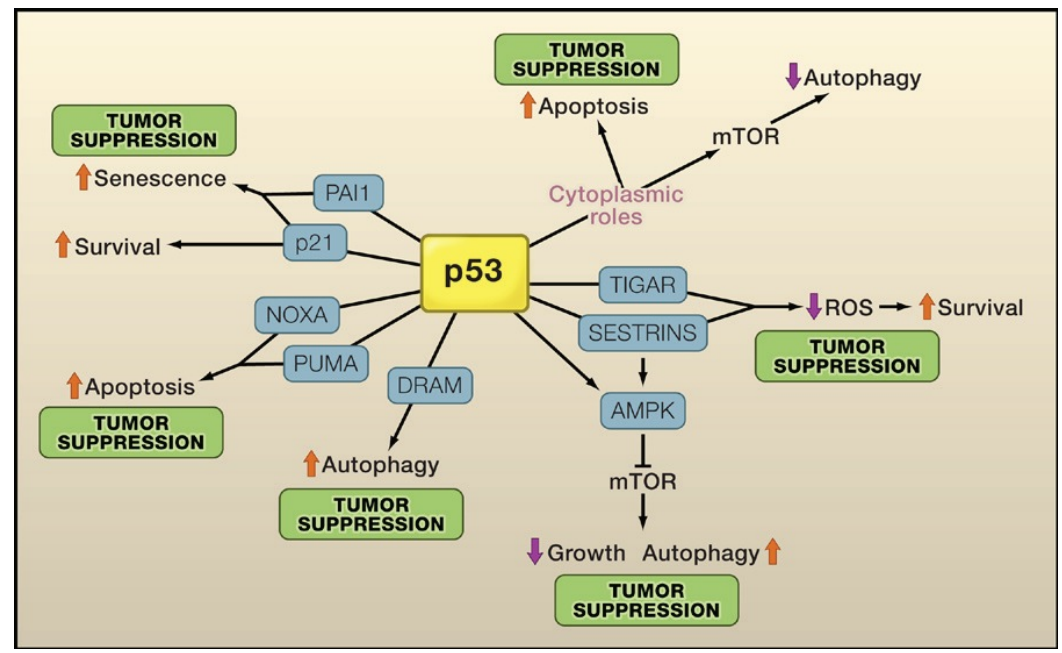

Figura 1. Funciones de p53. Extraído de Vousden, K. H. and Prives, C. 2009. Blinded by the light: the growing complexity of p53. Cell 137, 413- 431.

Más de la mitad de los cánceres conocidos en el ser humano albergan mutaciones en el p53; la herencia de un alelo mutado de este gen predispone al síndrome autosómico dominante Li-Fraumeni (Olivier y cols., 2010). Kezelmann Broz y Attardi en 2010 confirmaron el papel fundamental en la supresión de tumores utilizando p53null mice, demostrando una incidencia de cáncer del 100\% (Kezelmann y Attardi, 2010) (Figura 2).

En situaciones de alto nivel de estrés, p53 dirige de manera irreversible a la apoptosis o senescencia (detención irreversible del ciclo celular) de las células, seleccionando aquellas muy dañadas o malignas, siempre en beneficio del organismo. Bajo pequeños niveles de estrés, p53 tiende a preservar la vida de la célula, bien deteniendo temporalmente el ciclo celular, reparando el daño del ADN o produciendo proteínas antioxidantes. Todas estas respuestas, dependen de la habilidad de p53 como 
activador transcripcional de una gran variedad de genes, aunque la actividad independiente de la transcripción que se le atribuye a p53 puede también contribuir en las funciones descritas anteriormente (Colleen y Attardi, 2010).

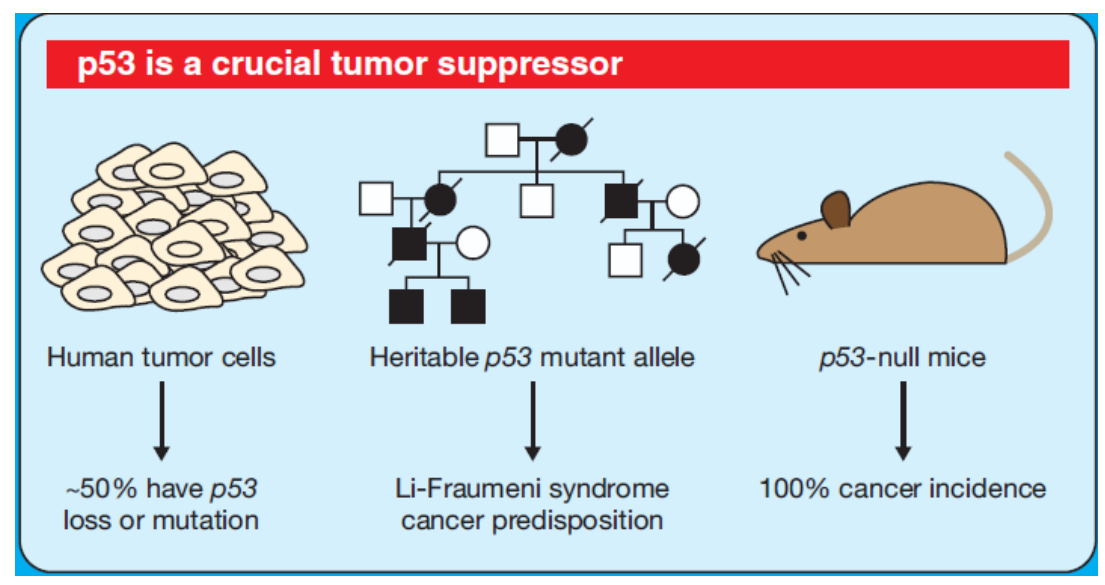

Figura 2. De izquierda a derecha. Un $50 \%$ de los cánceres en humanos presentan pérdida o mutación de p53. La herencia de un alelo mutado de p53 predispone al síndrome de Li-Fraumeni. En los ratones carentes de p53 se demostró una incidencia del 100\% de cáncer. Extraído de Collen y Attardi, 2010.

Las funciones de p53 son muchas y aunque entre las más importantes se encuentran las mencionadas (detención del ciclo celular y apoptosis), cada día son más los estudios de investigación que se cuestionan nuevas funciones y mecanismos de acción del p53; se le atribuyen continuamente nuevas acciones que afectan la supresión de tumores, incluyendo la regulación del metabolismo, autofagia y el estado oxidativo de la célula (Colleen y cols., 2010). Una función muy importante atribuida a p53 ha sido su papel como factor de transcripción y la regulación de una gran diversidad de genes, que posteriormente median en la respuesta de p53 (Vousden and Prives, 2009).

Una actividad inapropiada de p53 puede ir en contra de la viabilidad de la célula y el organismo, por lo que hay numerosos mecanismos para mantener a p53 bajo control. Muchas ubiquitin-ligasas E3, principalmente MDM2, pero también otras como PIRH2, COP1 y ARF-BP1, regulan negativamente los niveles de proteína p53, manteniendo los niveles bajos cuando no se requiere de su actividad (Brooks y Gu, 2006). MDM2 se une al TAD del p53 y no solo regula la estabilidad de p53, sino que también inhibe su función de transactivación bloqueando la incorporación de componentes transcripcionales esenciales. La importancia de MDM2 en la regulación de p53 se evidenció usando el Mdm2-null mice, los cuales mostraban una letalidad embrionaria muy temprana (Jones y cols., 1995; Montes de Oca Luna y cols., 1995). En respuesta a señales de estrés, p53 se moviliza por la inhibición de MDM2, a través de alguno de los muchos mecanismos que existen: modificaciones post-translacionales tanto en MDM2 como en p53 inducido por estrés, lo que rompe la interacción entre MDM2-p53; el secuestro de MDM2 inducido por oncogenes por el supresor de tumores ARF; la unión a proteínas ribosomales que desencadena estrés nucleolar y la inhibición de MDM2 
mediada por la ubiquitilación de p53 (Marine y cols., 2006; Wade y cols., 2010; Zhang y Lu, 2009). P53 por sí mismo también controla la función de MDM2 activando la transcripción del gen MDM2, proporcionando un feedback negativo para atenuar la señalización de p53 en el momento oportuno.

\section{$2.1 \quad$ Estructura de $\mathbf{p 5 3}$}

La proteína p53 activa es un tetrámero constituido por 4 subunidades idénticas (monómeros). Cada monómero está formado por dominios bien definidos. El dominio $\mathrm{N}$-terminal comprende a su vez dos dominios que activan la transcripción (TAD 1 y TAD 2); estos dominios pueden aumentar la transcripción de los genes diana de p53 de manera independiente reclutando enzimas modificadoras de histonas o complejos coactivadores como STAGA y Mediator (Gamper and Roeder, 2008) (Laptenko y Prives, 2006).

El dominio localizado centralmente y que está altamente conservado es el dominio de unión al ADN. Es el responsable de la unión de secuencias específicas de proteínas a los elementos respuesta a p53 en el ADN de sus genes diana. El dominio Cterminal está compuesto por un dominio de tetramerización seguido de dominio básico no estructurado (Laptenko y Prives, 2006; Brady y Attardi, 2010) (Figura 3).

De entre las más de 18.000 mutaciones actualmente conocidas de p53 que resultan en la pérdida, tanto parcial como total de sus funciones, la mayoría se encuentran en el dominio de unión del ADN. Estas mutaciones pueden interrumpir la unión específica al ADN de los genes diana de p53 de muchas formas distintas (Laptenko y Prives, 2006), resultando en la pérdida de las funciones supresoras de tumores. Del mismo modo, se conoce la capacidad de la proteína p53 mutada de adquirir nuevas funciones oncogénicas que modulan una amplia variedad de fenotipos tales como el incremento del crecimiento celular, la migración, invasión y metástasis, la inestabilidad genómica y la quimioresistencia (Oren y Rotter, 2010; Cadwell y Zambetti, 2001); de hecho, antes del descubrimiento del gen TP53, se pensaba que p53 funcionaba como un oncogen, esto fue debido a que todos los estudios fueron realizados con p53 mutados aislados de células tumorales (Eliyahu y cols., 1985; DeLeo y cols., 1979). 


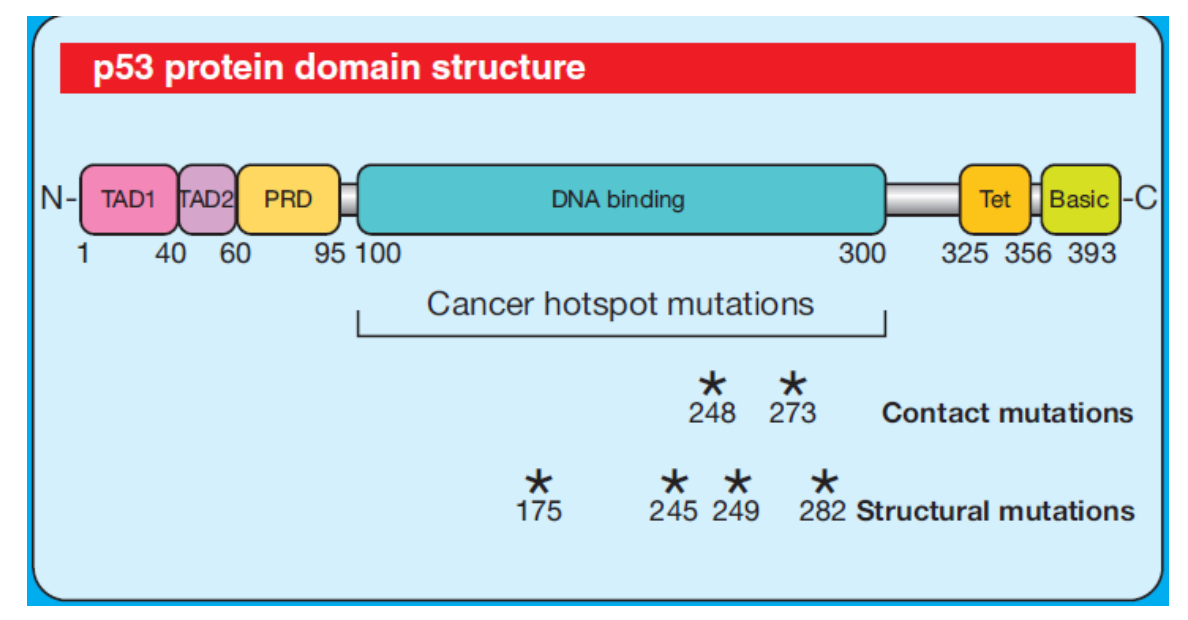

Figura 3. Estructura del monómero de p53.

\section{$2.2 \quad$ P53 y microARNs}

Los miRNAs son una clase de pequeños nucleótidos endógenos de ARN no codificantes. La mayoría de ellos actúan inhibiendo postranscripcionalmente la expresión de genes uniéndose a la región 3'-UTR de ciertos mARN, inhibiendo su estabilidad o su traslación (Li y cols., 2014). Los microARNs (miARNs) son potentes reguladores de la expresión genética y modulan múltiples procesos celulares incluyendo la proliferación, diferenciación y apoptosis, por lo que la perturbación de la expresión de los miARN tiene consecuencias patológicas (Kasinski y cols., 2011).

La regulación negativa de la expresión de los miARN se observa frecuentemente en los cánceres, lo que sugiere que la mayoría de los miARNs funcionan como supresores de tumores. Ejemplos de miARNs supresores de tumores incluye la familia let-7, la familia cluster miR-15-16, y el miR-34a, regulado transcripcionalmente por p53 (Hermeking, 2009). Como el mismo p53, miR-34 ejerce funciones supresoras de tumores inhibiendo la proliferación celular e induciendo la apoptosis; la expresión de miR-34 está silenciada en algunos tumores debido a la delección homocigótica o la pérdida de la señalización de p53 (Lal y cols., 2011; He y cols., 2007).

Aunque la mayoría de los miARNs actúan como supresores de tumores, algunos, incluidas la familia miR-17-92, miR-21 y miR-155 tienen una regulación positiva en ciertos cánceres, lo que sugiere que presentan funciones oncogénicas.

Como ya hemos señalado para miR-34, se ha demostrado que ciertos miARN son regulados por p53. En el caso de p53 mutado, no solo pierde su actividad como supresor de tumores, sino que también adquiere nuevas funciones oncogénicas que son independientes del p53 wt. Se ha visto que los miARNs son los efectores últimos de los procesos biológicos regulados por p53 mutado. Por lo tanto, una perspectiva importante para el cáncer es la conexión entre las vías de regulación de los miARN con las vías de regulación de p53 mutado (Li y cols., 2014). 


\subsection{P53 y CCR}

Como ya hemos hablado, el CCR constituye una proporción significativa en la carga global de morbilidad y mortalidad por cáncer (Center, y cols., 2009). Fearon y Vogelstein propusieron un modelo de carcinogénesis en el CCR que correlacionaba diferentes eventos genéticos con la evolución de la morfología de los tejidos. Cada paso entre la mucosa normal y el cáncer conlleva alteraciones genéticas específicas y bien definidas (Fearon, y cols., 1990). De acuerdo con este modelo, alteraciones en TP53, APC y DCC, así como en el oncogen K- ras son características. La mutación en el TP53 o su pérdida de función ocurre principalmente en la transición de adenoma a cáncer y la frecuencia de alteraciones del gen aumenta con la progresión de la lesión (Worhley, y cols., 2007).

La frecuencia de mutaciones en TP53 en el CCR es alrededor del 50\%, afectando principalmente a 5 codones que incluyen el 175, 245, 248, 273 y 282 (Tominaga, y cols., 2010; Soussi, y cols., 2003). Las mutaciones en el codón 175 ocurren con más frecuencia en tumores localizados en el colon y las mutaciones que implican el codón 288 en el exón 8 son más comunes en los cánceres rectales (Vidaurreta y cols., 2008). Las mutaciones que ocurren en las regiones más conservadas de TP53 son más frecuentes en los tumores distales comparados con los proximales, esto sugiere que puede estar en relación con las diferencias en la etiología (Oki y cols., 2009). Las mutaciones tanto por transversión (purina por pirimidina) como por transición (purina por purina; pirimidina por pirimidina) son más frecuentes en los tumores de colon distal. Como se mencionó anteriormente, las alteraciones genéticas ocurren en las últimas fases de la progresión del adenocarcinoma por lo tanto, las mutaciones en los adenomas colorrectales son raros $(16 \%)$, en comparación con la frecuencia de alteraciones genéticas en el carcinoma (40-50\%) (Iacopetta y cols., 2006). Las mutaciones más frecuentes encontradas tanto en carcinomas como en adenocarcinomas se encuentran en los codones 175 y 273 . Sin embargo, se ha observado que la mutación en el codón 248 es tres veces mayor en adenocarcinomas que en adenomas (Lea, y cols., 2009).

Hasta ahora, se han identificado 200 polimorfismos de un solo nucleótido en el TP53. Dada la alta frecuencia de variantes en los alelos de la población general, las mayoría de estas variaciones en el TP53 no causan más que sutiles efectos biológicos (Whibley y cols., 2009).

El polimorfismo más investigado es rs1042522, una transversión de G (guanina) a C (citosina) en el codón 72 del exón 4, cuyo resultado final es el cambio del aminoácido arginina por prolina (TP53 Arg72Pro). El polimorfismo rs1042522 se localiza en la región rica en prolina de la proteína, la cual se conoce por tener un importante papel en el control del crecimiento y en las funciones apoptóticas (Soussi y Lozano, 2005). Este polimorfismo conlleva un cambio estructural en la proteína, dando lugar a diferencias en la movilidad electroforética (Pietsch y cols., 2006).

Las dos isoformas de p53 debidas al polimorfismo en el codón 72 tienen diferentes propiedades tanto biológicas como bioquímicas. Al parecer, la forma Arg72 induce la apoptosis de manera más eficiente que la forma Pro72 (Pim y Banks, 2004). 
Muchas investigaciones han estudiado la asociación entre el polimorfismo Arg72Pro y el riesgo de cáncer colorrectal, incluyendo estudios que estudian el riesgo de adenomas. Varios estudios hablan de asociación entre CCR con el alelo Pro72 (Song y cols., 2011; Sameer y cols., 2010; Cao y cols., 2009; Zhu y cols., 2007). Además, este riesgo de padecer cáncer en los portadores del alelo Pro72 parece que aumenta en los consumidores de alcohol (Zhu y cols., 2007). En contraste a estos datos, dos estudios describen la asociación del alelo Arg72 con un aumento del riesgo de CCR (Perez y cols., 2006; Dakouras y cols., 2008), y uno de ellos muestra aumento del riesgo de adenoma (Koushik y cols., 2006).

Otro polimorfismo frecuentemente estudiado es la duplicación 16-bp en el intron 3 (PIN3, rs17878362. Los diferentes alelos se hacen llamar A1 y A2, siendo A2 el portador de la duplicación 16-bp). Se han llevado a cabo, de la misma manera que con Arg72Pro, muchos estudios que intentan mostrar la relación entre este polimorfismo y el riesgo de CCR, encontrando diversidad de resultados. Algunos de ellos muestran asociación entre un descenso del riesgo y el alelo A2, mientras otros informan de asociación con aumento del riesgo (Mammano y cols., 2009; Gemignani y cols., 2004).

Estudios han reportado asociación entre mutaciones somáticas del TP53 o expresión anormal de las proteínas con una peor supervivencia o una falta de respuesta a los tratamiento (Munro y cols., 2005). La mayoría de las investigaciones sobre la relevancia clínica de los polimorfismos de TP53 están centradas en el papel de Arg72Pro. In vitro, la variante $\operatorname{Arg} 72$ ha mostrado ser un mayor inhibidor de la apoptosis inducida por quimioterapia que la variante Pro72. Sin embargo, los pacientes homocigotos para el alelo Arg72, con cáncer de mama, pulmón, cabeza y cuello han mostrado más supervivencia y mejor respuesta a la quimio y radioterapia (Nacaratti y cols., 2012).

Un estudio basado en 3583 pacientes con CCR muestra más frecuencia de mutaciones en TP53 en tumores distales y de recto que en los proximales. La pérdida de aminoácidos que causan las mutaciones se asociaban con peor supervivencia, y pacientes con estadio C de Duke y wtTP53 tenían mejor supervivencia después del tratamiento adjuvante con quimioterapia (Russo y cols., 2005).

En el cáncer colorrectal, la alteración de la función normal de gen TP53 representa un gran paso en la carcinogénesis, aunque las mutaciones se han identificado como eventos tardíos en este proceso. Debido al papel fundamental del TP53, es esperable que sus variantes jueguen un papel en la susceptibilidad del CCR esporádico. A pesar de esto, no se dispone aún de resultados consistentes sobre la labor de las mutaciones en TP53 y sus polimorfismos (Naccarati y cols., 2012). 


\section{MELATONINA}

Descrita por primera vez por McCord y Allen en 1917 y aislada por Lerner en 1959, la melatonina o N-acetil-5-metoxitriptamina es una indolamina sintetizada principalmente en la glándula pineal, la cual posee todas las enzimas necesarias para su síntesis a partir de la serotonina (Axelrod, 1978).

Estudios recientes muestran, con la ayuda de anticuerpos específicos de melatonina, la presencia de esta indolamina en múltiples tejidos extrapineales como el cerebro, la retina, cóclea, epitelio respiratorio, glándula de Harder, piel, tracto gastrointestinal, hígado, riñones, tiroides, páncreas, timo, bazo, sistema inmune, tracto reproductivo y células endoteliales. La melatonina está presente en la mayoría de los fluidos biológicos, excediendo muchos de ellos las concentraciones de la sangre (Acuña-Castroviejo y cols., 2014).

\subsection{Síntesis y regulación de melatonina}

La síntesis de melatonina ocurre en el pinealocito, con una oscilación diaria, dependiendo de las condiciones lumínicas, ya que la luz suprime su actividad, habiendo un aumento de su secreción durante la noche, considerándose un marcador endocrino nocturno. (Reiter RJ, 1991).

La síntesis comienza con el aminoácido triptófano, que pasa a 5-hidroxitriptófano gracias a la enzima triptófano-hidroxilasa. Es la enzima L-aromático- aminoácidodecarboxilasa la que convierte el 5-hidroxitriptófano en 5-hidroxitriptamina o serotonina. En una segunda etapa la serotonina se acetila por para formar la Nacetilserotonina por el enzima citosólico arilalquilamina-N-acetiltransferasa (AA-NAT). La serotonina acetilada se convierte en melatonina o $\mathrm{N}$-acetil-5-metoxitriptamina por la $\mathrm{N}$-acetilserotonin-O-metiltransferasa (ASMT) (antes llamada hidroxindol-Ometiltransferasa (HIOMT)) (Stehle y cols., 2011) (Figura 4).

La producción circadiana de la melatonina en la glándula pineal explica su influencia cronobiótica en la actividad del organismo, incluyendo tanto los ritmos endocrinos como los no endocrinos. Otras funciones de la melatonina incluye propiedades antioxidantes y antiinflamatorias, efectos sobre el genoma y su capacidad para modular la homeostasis de la mitocondria que está ligada al estado rédox de las células y los tejidos (Acuña-Castroviejo y cols., 2014).

El 90\% de la hormona se desactiva a nivel hepático y es eliminada vía renal en forma de 6-hidroximelatonina. Sus niveles en orina se pueden utilizar para valorar el nivel hormonal en sangre (Arendt y cols., 2006).

La producción de melatonina parece disminuir gradualmente con la edad, comenzando su síntesis a los tres o cuatro meses de edad, alcanzando su máximo entre los ocho o diez años y disminuyendo su síntesis paulatinamente, hasta que por encima de los 70 años los niveles de la hormona no superan el $10 \%$ de los prepuberales (Guerrero y cols., 2007; Mishima y cols., 2001) 


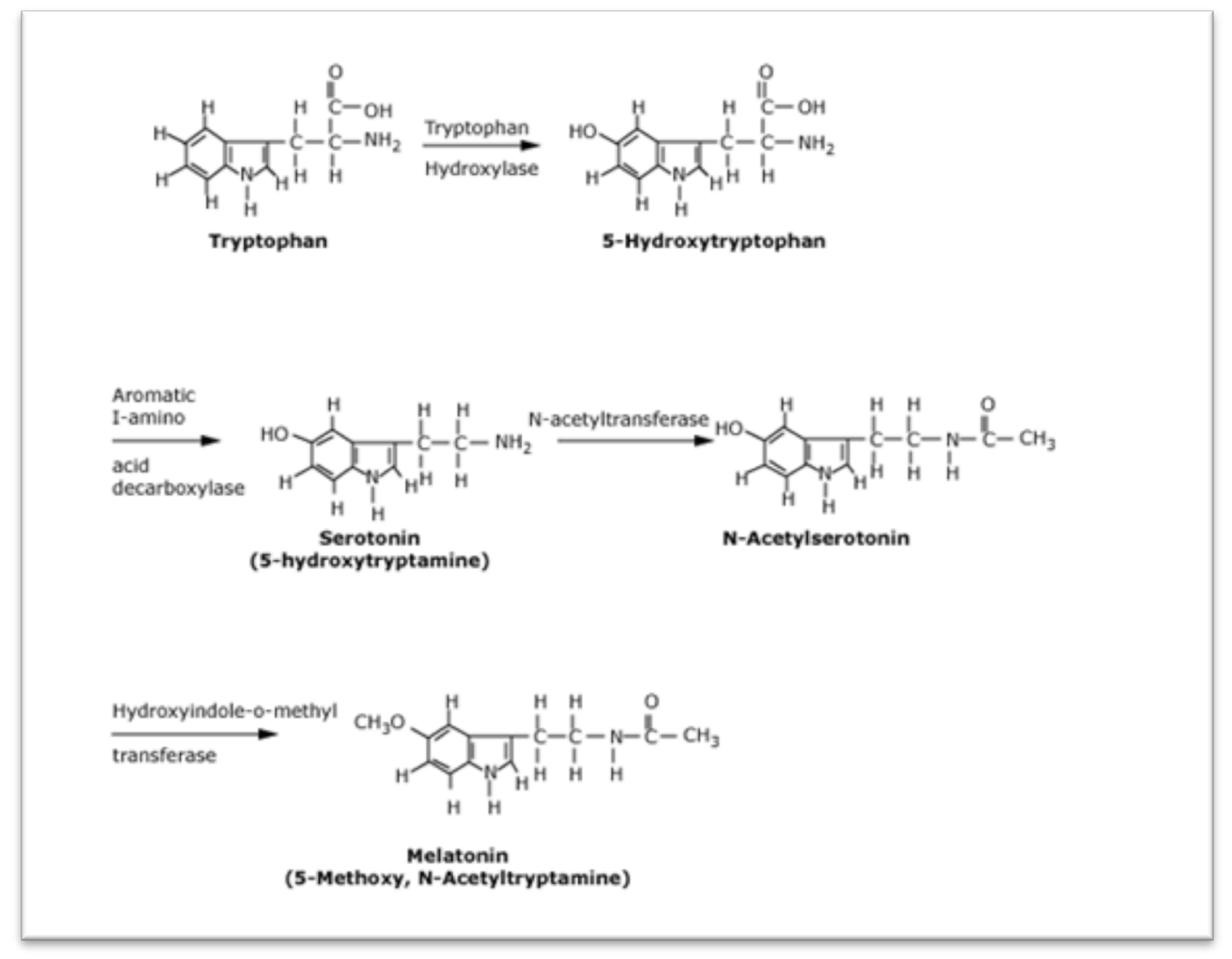

Figura 4. Metabolismo del triptófano a melatonina en la glándula pineal. Extraído de: Zhdanova, IV, Wurtman, RJ. In: Endocrinolody: Basic and Clinical Principles, PM, Conn, S, Melmed (Eds), Humana Press, Inc, Totowa, NJ, 1997, p.281.

\subsection{Receptores de melatonina}

Los efectos de la melatonina están mediados por dos mecanismos diferentes: dependientes de receptores y no dependientes de receptores.

Los receptores pueden ser de membrana o nucleares. Entre los primeros encontramos dos tipos, MT1 y MT2, los cuales pertenecen a la familia de los receptores acoplados a proteína G (Dubocovich y cols., 2005; Reppert y cols., 1995). Se ha descrito un tercer lugar de unión de la melatonina, MT3, identificado como una quinona reductasa 2, relacionada en el metabolismo xenobiótico de la célula, sin embargo no reúne todos los criterios para ser clasificado como receptor de melatonina (Nosjean y cols., 2000).

La activación del receptor MT1 conduce a diferentes respuestas, la mayoría de ellas dependientes de la inhibición del AMPc, a través de la proteína G (Brydon y cols., 1999). MT1 está relacionado con funciones metabólicas, reproductivas y vasocontricción (Dubocovich y cols., 2005). La unión de la melatonina a MT2 conlleva una inhibición de AMPc y del GMPc (Petit y cols, 1999). Este segundo receptor está 
relacionado con el control de los ritmos circadianos y la liberación de dopamina en la retina, así como en la vasodilatación, entre otras acciones (Dubocovich y cols., 2005).

Los receptores nucleares de la melatonina denominados 'receptores huérfanos ROR' incluyen tres subtipos $(\alpha, \beta$ y $\gamma$ ) y cuatro variantes del subtipo $\alpha$ (Becker-Andre y cols., 1994). Sólo la variante c del subtipo ROR $\alpha$ y el ROR $\gamma$ están relacionados con la acción de la melatonina en el núcleo. Algunos de sus efectos genómicos están asociados a la interacción con estos receptores (Wiesenberg y cols., 1998).

La melatonina también interactúa con varias proteínas citosólicas incluyendo la calmodulina, involucrada en la regulación del citoesqueleto, la calreticulina encargada del control de los receptores nucleares y la PKC (Benitez-King y cols., 1993).

La melatonina actúa, de forma directa como scavenger de radicales libres, generándose, durante su interacción con especies reactivas de oxígeno (EROS) y especies reactivas del nitrógeno (ERN), una serie de intermediarios que actúan a su vez como neutralizadores de radicales libres. Esta función también es capaz de realizarla de manera indirecta, provocando un aumento de la expresión y actividad de enzimas antioxidantes endógenos. Este mecanismo, relacionado inicialmente como efecto de la melatonina sobre el receptor ROR $\alpha$ (Tomás-Zapico y Coto-Montes, 2005), parece depender también de la activación de los receptores de membrana (Venegas y cols., 2012).

Aunque la mayoría de los autores hablan de los efectos antioxidantes de la melatonina, en algunos casos puede tener efecto pro-oxidante, ocurriendo principalmente en células que están muy dañadas o células cancerígenas. Los efectos duales de melatonina sobre el estado rédox intracelular incluye una respuesta antioxidante/antiproliferativa o bien un efecto pro-oxidante/citotóxico (SánchezSánchez y cols., 2011). Este efecto pro-oxidante puede explicar las acciones oncostáticas atribuidas a la melatonina. Esta última función puede servir de control sobre el destino de ciertas células, promoviendo en última instancia respuestas proapoptóticas para eliminar células potencialmente malignas.

\subsection{Melatonina y tracto gastrointestinal}

En el tracto gastrointestinal (TGI) la melatonina es sintetizada en las células enterocromafines de la mucosa. Los niveles en el TGI son 400 veces mayor que en la glándula pineal y de 10 a 100 veces mayores que los niveles en suero (Bubenik, 2008).

Una parte de la melatonina del TGI proviene de la dieta (Acuña-Castroviejo y cols., 2014), aunque parte también es producida por la flora intestinal, la bilis y otros tejidos. Además de la producción de melatonina atribuída a las células enterocromafines, se ha demostrado el TGI puede acumular melatonina e la circulación (Bubenik, 1980).

Hace décadas se determinó que la síntesis de melatonina en el TGI no variaba después de la pinealectomía, hecho que se confirmó en 1997 por Bubenik y Brown, los cuales no encontraron diferencias en las concentraciones de melatonina del TGI de ratas pinealectomizadas y los controles (Bubenik y Brown, 1997). Esto junto a la presencia 
de enzimas AANAT y ASMT apoyan la afirmación que de la síntesis de melatonina en el TGI es independiente de la pineal (Acuña-Castroviejo y cols., 2014).

La melatonina del TGI es un compuesto multifuncional con efectos tanto generales como específicos del tejido donde se encuentra. (Bubenik, 2008). Mientras que la melatonina producida en la glándula pineal actúa mayormente como una sustancia endocrina, en el TGI tiene funciones tanto endocrinas, paracrinas, autocrinas y luminales (Bubenik y cols., 1999; Chow y cols., 1997). Generalmente, la secreción episódica de melatonina en el TGI está relacionada con la toma y digestión de alimentos y con la prevención del daño tisular causado por el ácido clorhídrico y las enzimas digestivas. Ya hemos comentado algunas de las acciones generales de esta hormona, tales como scavenger de radicales libres o sus efectos antioxidantes, sin embargo en el TGI ejerce efectos específicos como el aumento del flujo sanguíneo de la mucosa, reducción de la peristalsis o la regulación del contenido de agua en las heces (Bubenik, 2008).

Las acciones de la melatonina, contrarrestan las de la serotonina. Este hecho se establece por primera vez in vitro en 1965 por Quastel y Rahamimoff, analizando el efecto de la melatonina sobre la peristalsis (Quastel y Rahamimoff, 1965). Mientras que la serotonina induce contracciones espásmicas in vivo, la melatonina quita el espasmo y reanuda la peristalsis (Bubenik, 2008). La acción de la melatonina en el músculo liso del intestino parece estar mediado por los receptores MT2 (Luchcelli y cols., 1997).

\subsection{Melatonina y cáncer}

Es reconocido que la melatonina tiene propiedades oncostáticas en una gran variedad de tumores, especialmente en aquellos que son hormono-dependientes. Los mecanismos que pueden estar involucrados en la habilidad de la indolamina de contrarrestar el crecimiento tumoral son variados, incluyendo:

- Efectos antioxidantes.

- Regulación en la transactivación y expresión de los receptores de estrógenos.

- Control de las enzimas involucradas en la síntesis local de estrógenos.

- Control del ciclo celular y la inducción de apoptosis.

- Inhibición de la actividad telomerasa.

- Inhibición de metástasis.

- Prevención de la alteración del ritmo circadiano.

- Antiangiogénesis.

- Efectos epigenéticos.

- Estimulación de la diferenciación celular.

○ Activación del sistema inmune (Mediavilla y cols., 2010).

Un metaanálisis realizado en 2012 muestra un efecto significativamente positivo del uso de la metatonina oral en pacientes con cáncer, bien en monoterapia o bien combinada con algún tipo de quimioterapia. Estos beneficios se observaron en las tasas de supervivencia, de respuesta al tratamiento y en el perfil de toxicidad de una variedad 
de fármacos quimioterápicos. Es importante resaltar que los resultados beneficiosos de la melatonina demostraban efectos similares en distintos tipos de cáncer. Este trabajo confirmó un aumento de la supervivencia en un año en pacientes con cáncer que recibía tratamiento con melatonina (Seely y cols., 2012).

\subsection{Melatonina y CCR}

Los pacientes con cáncer colorrectal muestran una disminución de la concentración nocturna de melatonina en plasma (Kos-Kudla y cols., 2002). Varios estudios con ratas pinealectomizadas sugieren que la melatonina está implicada en la carcinogénesis de este tipo de cáncer (Dalio y cols., 2006). En estudios in vitro la melatonina inhibe el crecimiento celular e induce apoptosis a dosis nano y milimolares. In vivo también se ha demostrado la inhibición del crecimiento de tumores colorrectales (Anisimov y cols, 2000; Tanaka y cols., 2009).

La mucosa del colon expresa receptores de andrógenos (AR) y receptores de estrógenos (ER) $\alpha$ y $\beta, \mathrm{y}$ una disminución en su expresión se ha relacionado con la progresión del CCR (Castagnetta y cols., 2002). Recientemente se ha demostrado un descenso de la expresión de los receptores MT1 y MT2 en el CCR, lo que a su vez parece estar correlacionado con el estadio tumoral y el género (León y cols., 2012). De hecho, la expresión de MT1 puede verse afectada por los estrógenos (Clemens y cols., 2001) y andrógenos (Ahmad y cols., 2010). La expresión de AANAT también desciende en CCR respecto al colon normal, mientras que ASMT no varía (León y cols., 2014).

Por otra parte tanto MT1 y MT2 como los receptores nucleares de la melatonina parecen estar implicados en su acción oncostática. La indolamina está implicada en la regulación de la inmunidad a través de su unión a receptores de distintas células del sistema inmune. La activación de linfocitos y monocitos/macrófagos por la melatonina, es uno de los mecanismos por los que la indolamina inhibe el crecimiento tumoral (Chen CQ y cols., 2011).

En un estudio realizado con células HCT116 de cáncer colorrectal, las cuales se trataron con $10 \mu \mathrm{M}$ de melatonina, se encontró que la hormona era capaz, a estas concentraciones, de activar la apoptosis y la autofagia de las células tumorales, así como inducir un parada del ciclo celular en G1 (Hong y cols., 2014).

En modelos in vitro de CCR, se ha demostrado que la melatonina inhibe el crecimiento tumoral debido a la inhibición de la expresión del RNAm del gen endotelina-1, implicado en crecimiento y progresión en multitud de tumores (León y cols., 2014). En este caso, se ha demostrado que la melatonina inhibe la expresión de este gen debido a la inactivación de FoXO-1, asociado a un aumento de la concentración de Camp, activación de PKA y aumento de la concentración de fosfo-Src (pSrc), y a la inactivación de NF- $\kappa$, asociado a la inhibición de la actividad PKC que bloquea la fosforilación de Akt y ERK (León y cols., 2014). 


\subsection{Melatonina y p53}

Recientemente se ha demostrado que la melatonina inducía la fosforilación del p53 en el residuo Ser-15, inhibiendo de esta manera la proliferación celular y previniendo el daño acumulado en el ADN tanto de células normales como mutadas. Todo esto requiere de la expresión de p53, de la proteína PML (promyelocytic leukemia) y una fosforilación eficiente del p53 en el residuo Ser-15 (Santoro y cols., 2012). El residuo Ser-15 se fosforila por la kinasa mutada de ataxia teleangiectasia (ATM) en respuesta a radiación $\gamma$, mientras que p38 mitogen-activated protein kinasa (MAPK) conduce a la fosforilación de p53 en respuesta a la radiación UV. ATM y ataxia teleangiectasia related fosforilan p53 cuando existen roturas dobles de la cadena de ADN, mientras que P38 es capaz de fosforilzar p53 en respuesta a roturas de una sola cadena del ADN o en ausencia de ATM (She y cols., 2000). Señalar que la fosforilazión inducida por melatonina del p53 no requiere de la actividad de ATM; al contrario, la inhibición de la acitividad de p38 MAPK afecta la capacidad de la melatonina para inducir la respuesta al ADN dañado dependiente de p53 y su habilidad para mantener la integridad del genoma, dado que se suprime la fosforilación de p53 en el residuo Ser15. Esta acción de la melatonina requiere también de la presencia de H2AX (Santoro y cols., 2013).

En todo esto proceso de activación de p53 por la melatonina participan los receptores MT1 y MT2. Estos receptores transmembrana acoplados a proteína G, en presencia de ligando, activan la proteína $G$ e inhiben la formación de AMPc comenzando así una cascada que terminará en la fosforilazión de p53. Se ha demostrado, por tanto, que la melatonina desencadena la fosforlización de p53 a través de la activación de MT1 y MT2. De hecho, tanto la inhibición química como el silenciamento génico de estos receptores afecta a la habilidad de la melatonina para activar la fosforilación de p38 y su acumulación, y por tanto inhibiendo la fosforilación de p53 (Santoro y cols., 2013). 


\section{HIPÓTESIS Y OBJETIVOS}

Existe una relación entre el descenso de la síntesis y la señalización intracelular de melatonina y el CCR (León y cols., 2012, 2014). En este tipo de cáncer, se ha demostrado que la activación (fosforilación) de p53 también depende, al menos en parte, de la melatonina a través de sus receptores de membrana. El hecho de que el gen TP53 se encuentre mutado en la mayoría de los cánceres y, en particular en el CCR, nos ha llevado a plantear la siguiente hipótesis: "La expresión de los enzimas de síntesis y de los receptores de membrana de melatonina está relacionada con el estatus del gen TP53 en el CCR".

Para responder a la hipótesis, se han planteado los siguientes objetivos:

1. Determinar la expresión de MT1, MT2, RORa, AANAT y ASMT en muestras de pacientes con CCR y su relación con el estatus del gen TP53 (mutado o no mutado).

2. Analizar la expresión de MT1, MT2, ROR $\alpha$, AANAT y ASMT en líneas celulares establecidas de cáncer de colon con diferente estatus del gen TP53. 


\section{MATERIALES Y MÉTODOS}

\section{Cultivos celulares}

Para este estudio se han utilizado cuatro líneas celulares establecidas de colon: RKO y HCT-116 (TP53 salvaje); y HT-29 y DLD-1 (TP53 mutado). Todas ellas se han obtenido de la ATCC, a través del Servicio de Cultivos Celulares del Centro de Instrumentación Científica de la Universidad de Granada.

Para su mantenimiento y propagación, todas ellas se han cultivado en medio RPM1 1640 (Gibco) al 10\% de suero bovino fetal y con antibiótico-antimicótico al 1\% (penicilina, estreptomicina y anfotericina).

\section{Pacientes}

El Comité de Ética del Hospital Universitario San Cecilio, aprobó el estudio de muestras humanas de CCR, y todos los pacientes dieron su consentimiento informado (Anexo 1) por escrito para el almacenamiento de las muestras después de la cirugía en la Red de Banco de Tumores de Andalucía (RBTA), y para su posterior utilización en la investigación biomédica.

Todas las muestras se obtuvieron entre las 9 horas a.m. y las 12 horas del mismo día (3 horas), y los tejidos tumorales viables y los tejidos normales adyacentes, fueron diseccionados de forma inmediata y congelados en fresco en Tissue-Tek1 (Optimal Corte compuesto Temperatura, Sakura Finetek Europa B.V., Zouterwoude, Países Bajos), por métodos estándar.

Los ARNm de AANAT, ASMT, ROR $\alpha$, MT1 y MT2 se evaluaron en el tejido tumoral y mucosa normal adyacentes de 177 pacientes (edad media $70 \pm 11$ años) que se sometieron a cirugía para tratamiento de CCR primario esporádico. Las características de los pacientes se muestran en la Tabla 2. La normalización de resultados se realizó utilizando el gen UBC como housekeeping. La extracción de ARNm se realizó de acuerdo a la sección 3 de este apartado. Los valores de Ct obtenidos mediante PCR a tiempo real (Sección 5 de este apartado de Materiales y Métodos) mediante curvas patrón realizadas a tal efecto para cada gen.

En relación con la estadificación del tumor (clasificados de acuerdo con la nomenclatura TNM), las muestras se agruparon en precoces (estadios I y II) y tumores avanzados (estadios III y IV), porque no se encontraron diferencias en los parámetros analizados para cada grupo por separado. 
TABLA 2: Características de los pacientes

\begin{tabular}{|l|c|}
\hline \multicolumn{1}{|c|}{ Características } & N (\%) \\
\hline Género & \\
\hline Hombre & \\
Mujer & $103(48.5)$ \\
Localización & $73(41.5)$ \\
\hline Colon & \\
Recto & $152(93.3)$ \\
\hline Tipo Histológico & $11(6.7)$ \\
\hline Bien diferenciado & \\
Moderadamente diferenciado & $47(28.1)$ \\
Pobremente diferenciado & $102(61.1)$ \\
\hline Estadio PTMN & $18(10.8)$ \\
\hline I & \\
II & $23(13.3)$ \\
IV & $63(36.4)$ \\
\hline
\end{tabular}

\section{Extracción de ARN}

El ARN total de las muestras de tejido, se preparó usando el RNeasy Mini Kit (QIAGEN). El procedimiento es el siguiente:

- Las células se cultivaron en placas de 6 pocillos a una densidad de 300.000 células/pocillo. Transcurrido el tratamiento, se aspiró completamente el medio de cultivo, se realizó un lavado con PBS y se lisaron directamente en los pocillos con $500 \mu$ l de tampón RLT. El producto de lisis se arrastró con rasqueta y se recogió con una pipeta en un tubo eppendorf $(1.5 \mathrm{ml})$ asegurándonos que no se producían grumos.

- Al lisado anterior se le añadieron $500 \mu \mathrm{l}$ de etanol al $70 \%$ para homogenizar el lisado, mezclando suavemente con la pipeta.

- Seguidamente, se transfirieron $700 \mu$ de la mezcla en una mini columna con un tubo recolector de $2 \mathrm{ml}$ y se centrifugó durante 15 segundos a 10,000 rpm. El líquido recogido en el tubo de $2 \mathrm{ml}$ se desechó.

- A la columna se le añadieron $700 \mu 1$ de tampón RW1 y se centrifugó durante 15 segundos a 10,000 rpm para lavar la membrana de la columna. Desechar el líquido recogido en el tubo colector.

- Se añadieron $500 \mu 1$ de tampón RPE (al 80\% de etanol) a la columna y se centrifugó durante 15 segundos a 10,000 rpm, para lavar la membrana de la columna. 
- Posteriormente, se reemplazó el tubo colector por uno nuevo y se eluyó el ARNm retenido en la columna con 30-50 $\mu$ l de agua ultrapura mediante centrifugación durante 1 minuto a 10,000 rpm.

La cantidad de ARN total se determinó por espectrofometría UV en un nanodrop (IMPLEN).

\section{Síntesis de ADNc}

El ADNc de cadena simple se preparó mediante transcripción inversa con primers oligo-dT, utilizando $2 \mu \mathrm{g}$ del total de ARN en $50 \mu \mathrm{l}$ de volumen total y empleando un kit comercial (AccuScriptTM High Fidelity 1st Strand cADN Synthesis Kit, Stratagene). La integridad del ADN se evaluó mediante electroforesis en gel de agarosa.

\section{PCR a tiempo real}

Unos $5 \mu 1$ de ADNc se amplificaron durante 40 ciclos con primers específicos para ubiquitina C (UBC), MT1, MT2, AA-NAT y ASMT, (Tabla 1). Las reacciones de PCR que contienen la mólecula SYBR-green fueron amplificadas en un equipo de PCR a tiempo real (Mx3000P QPCR System, Stratagene). Los datos fueron adquiridos como valor de ciclo umbral $(\mathrm{Ct})$. La amplificación de UBC se utilizó como estándar interno de ARNm para normalizar las diferencias en concentración de la muestra y de la carga. Se construyeron curvas de calibración para cada uno de los genes de estudio mediante el trazado de los valores de $\mathrm{Ct}$ frente a diluciones de ADNc conocidas. Después de cada experimento se realizó electroforesis en gel de agarosa de cada muestra, para descartar los productos de PCR no específicos y los dímeros de los primers.

Tabla 3: Cebadores utilizados en este estudio

\begin{tabular}{|c|c|c|c|}
\hline GEN & CEBADOR SENTIDO & CEBADOR ANTISENTIDO & $\begin{array}{c}\text { TAMANO } \\
\text { (PB) }\end{array}$ \\
\hline MT1 & ttgtccttttgccatttgctgggctcctc & gtcatcagtggagacggtttccatttaacc & 289 \\
\hline MT2 & gtggtgtttgtgatcttgccatctgctgg & agcatctgcctggtgctgcacaccaatgat & 321 \\
\hline ROR $\alpha$ & ttgtactgatgtcagcagatcgctcatggc & gctggctcaaattctgaagtgaacaactcc & 277 \\
\hline AA-NAT & tccetgccagtgagtttcgctgcctcac & tgtcccagagcgagccgatgatgaaggc & 206 \\
\hline ASMT & catgactgggcagacggaaa & gttagttccaggtcacaagaacagtt & 300 \\
\hline UBC & tgggatgcaaatcttcgtgaagacctgac & accaagtgcagagtggactctttctggatg & 213 \\
\hline
\end{tabular}




\section{Extracción de ADN}

Hemos realizado la extracción de $\mathrm{ADN}$ de las muestras procedentes de los tumores empleado la extracción de ADN con el kit de QIAamp ADN mini Kits (Qiagen).

El procedimiento es el siguiente:

- Los cortes recibidos del banco de tumores estaban incluidos en OCT. Recibíamos aproximadamente entre 15 y 20 cortes los cuales oscilaban entre 20-30 mg de tejido de colon. Estos eran mezclados con $180 \mathrm{ml}$ Buffer ATL.

- Posteriormente se añadieron $20 \mathrm{ml}$ de proteinasa $\mathrm{K}$, se mezclaron por vortex, e incubaron a $55^{\circ} \mathrm{C}$ hasta que el tejido estuvo completamente lisado. Se pueden dejar desde dos horas hasta el día siguiente, Se mezclaron con vortex ocasionalmente para facilitar el proceso de disgregación de la muestra. El resultado de la digestión suele ser viscoso pero un aspecto demasiado gelatinoso puede taponar la columna, por lo que en esos hubo que digerir de nuevo menos cantidad.

- Las muestras se trataron con Rnasa. Se añadieron $4 \mathrm{ml}$ de RNasa A (100 mg/mL), se mezclaron en vortex e incubaron 2 minutos a temperatura ambiente.

- De nuevo vortex durante 15 s. Añadimos $200 \mathrm{ml}$ de Buffer AL a la muestra, mezclamos completamente por vortex e incubación a $70^{\circ}$ durante $10 \mathrm{~min}$.

- Posteriormente añadimos $200 \mathrm{ml}$ de etanol absoluto (96 - 100\%) a la muestra y la mezclamos completamente con el vortex. Es muy importante que el Buffer AL, y el etanol fuesen mezclados hasta obtener una mezcla homogénea. Se puede formar un precipitado blanco cuando se añade el etanol. Este contiene el ADN de la muestra. Por esto es fundamental que añadir todo el precipitado a la columna QIAamp spin en el paso siguiente.

- Pipeteamos la mezcla del paso 5 dentro de la columna que se encuentra en un tubo de recolección de $2 \mathrm{~mL}$. Centrifugamos a 6000 x g $(8000 \mathrm{rpm}) 1 \mathrm{~min}$. Descartamos el líquido que pasa al tubo de recolección.

- Colocamos la columna en otro tubo de recolección de $2 \mathrm{~mL}$, Añadimos $500 \mathrm{ml}$ Buffer AW1, y centrifugamos $1 \mathrm{~min}$ a 6000 x g (8000 rpm) Vaciar el líquido del tubo de recolección.

- Colocamos la columna en otro tubo de recolección de $2 \mathrm{~mL}$, añadimos $500 \mathrm{ml}$ de Buffer AW2, y centrifugamos 3 minutos a velocidad máxima para secar la membrana de la columna. Descartamos lo que pasó por la columna y el tubo de recolección. Esta centrifugación elimina todo el etanol residual. Es importante evitar toda contaminación con el etanol contenido en el Buffer AW2 (tanto este buffer como el AW1 se preparan resuspendiendo con alcohol absoluto).

- Colocamos la columna QIAamp spin en un tubo de microcentrífuga limpio de 1.5 $2 \mathrm{~mL}$ y pipeteamos $200 \mathrm{ml}$ de Buffer AE o H2O mQ directamente a la membrana. Incubamos a temperatura ambiente por $1 \mathrm{~min}$, y luego centrifugamos 1 min a ${ }^{3} 6000$ x g (8000 rmp) para eluir. Eluir con $100 \mathrm{ml}$ (en vez de $200 \mathrm{ml}$ ) aumenta la concentración final de ADN en el eluído, pero también disminuye la cantidad de DNA que se obtiene. Esta cantidad es más que suficiente para nuestros propósitos. 
- Determinar el rendimiento de ADN obtenido.

a. Diluir $20 \mathrm{ml}$ de muestra de ADN en $980 \mathrm{ml}$ de agua desionizada y estéril (H2O mQ) (dilución 1/50)

b. Medir absorbancia a $260 \mathrm{~nm}$ usando cubetas de $1 \mathrm{ml}$, que puedan usarse a luz ultravioleta.

c. La concentración de $\mathrm{ADN}$ a $\mathrm{A}_{260}=1.0$ en una cubeta de $1 \mathrm{~cm}$ equivale a $50 \mathrm{mg}$ de DNA por ml de agua. Para calcular la concentración de la muestra:

$[\mathrm{ADN}]=50 \mathrm{mg} / \mathrm{ml} \times \mathrm{A}_{260} \times$ factor de dilución (50)

$[\mathrm{ADN}$ total $]=[\mathrm{ADN}] \mathrm{x}$ volumen eluído en $\mathrm{ml}$

\section{Determinación de las mutaciones del gen TP53}

Se puede dividir en las siguientes etapas:

7.1 EXTRACCIÓN ADN. (Como ya se ha descrito en el apartado anterior).

\subsection{AMPLIFICACIÓN ADN CON PRIMERS QUE FLANQUEAN LOS EXONES EN REGIONES INTRÓNICAS.}

A. Diseño de primers para amplificación

El gen P53 o TP53 está situado en el brazo corto del cromosoma 17 (17p13) y codifica una proteína de $43,7 \mathrm{kDa}$. Tiene un total de 26204 nucleótidos repartidos entre 11 regiones exónicas y 12 intrones que los flanquean. El exón 1 (5001-5169) codifica la región UTR5' del mARN. El intrón que lo separa del siguiente exón es de gran tamaño.

Los exones 2 y 3 son de muy pequeño tamaño. Hemos diseñados primers para amplificar estos exones más el exón 4 de modo que obtuvimos un fragmento propicio para ser secuenciado: Exón 2 (15924-16025), Exón 3 (16143-16164) y Exón 4 (16274-16552).

- Primer Sen p53(2-4): agctgtctcagacactggcatggtgttgg

- Primer Ant p53(2-4): cactgacaggaagccaaagggtgaagagg cctcttcaccctttggcttcctgtcagtg (secuencia 5'-3' del genoma original).

Asimismo hemos agrupado los exones Exón 5 (17310-17493) y Exón 6 (17575-17687) para diseñar primer de amplificación.

- Primer Sen p53(5-6): gttgctttatctgttcacttgtgccctgac

- Ant p53(5-6): tagggaggtcaatatagcagcaggagaaag cttctcctgctgcttattgacctcccta (secuencia 5'-3' del genoma original). 
En tercer lugar agrupamos la amplificación de los exones 7, 8 y 9: Exón 7 (18256-18365), Exón 8 (18709-18845), Exón 9 (18938-19011), mediante los primers:

- Sen p53(7-9): cagcctgggcgacagagcgagattccatc

- Ant p53(7-9): aaccaggagccattgtctttgaggcatcac gtgatgcctcaaagacaatggctcctggtt (secuencia 5'-3' del genoma original).

Por último amplificamos el Exón 10 (21831-21937) con la pareja de primer:

- Sen p53(10): tacttgaagtgcagtttctactaaatgcatg

- Ant p53(10): aggaagactaaaaaaatgtctgtgcagggc gccctgcacagacattttttagtcttcct (secuencia 5'-3' del genoma original).

El Exón 11 (22856-24144) incluye la UTR3', la cual es de gran tamaño. Esta región no ha sido secuenciada.

En cada exón amplificamos un fragmento variable de los intrones que lo flanquean. Los criterios empleados para la elección de los primers son los considerados adecuados por la comunidad científica. Entre ellos la no formación de dímeros, ni estructuras secundarias, repeticiones de nucleótidos, $\mathrm{n}^{\mathrm{o}}$ de nucleótidos, alta $\mathrm{T}^{\mathrm{a}}$ de hibridación, etc. Es por ello que en cada caso se elige la región intrónica que mejor cumple estos criterios y está cercana a los exones. Una vez propuestas las parejas de primers se evaluaron con el programa primer 6 para comprobar que van a cumplir su función con la máxima eficiencia posible y son admisibles termodinámicamente: dímeros repeticiones, horquillas, etc.

La proteína sintetizada tiene la siguiente secuencia.

meepqsdpsvepplsqetfsdlwkllpennvlsplpsqamddlmlspddieqwftedpgpdeaprmpe aaprvapapaaptpaapapapswplsssvpsqktyqgsygfrlgflhsgtaksvtctyspalnkmfcqla ktcpvqlwvdstpppgtrvramaiykqsqhmtevvrrcphhercsdsdglappqhlirvegnlrveyld drntfrhsvvvpyeppevgsdcttihynymcnsscmggmnrrpiltiitledssgnllgrnsfevhvcacp grdrrteeenlrkkgephhelppgstkralsnntssspqpkkkpldgeyftlqirgrerfemfrelnealelk daqagkepggsrahsshlkskkgqstsrhkklmfktegpdsd

B. Condiciones de PCR

Las PCRs se hicieron en un termociclador tipo 2720 Thermal de Applyed Biosystems del siguiente modo:

- Se empleó el kit de amplificación de Taq PCR ADN Polymerase, siguiendo las instrucciones del fabricante.

- Se añadieron 20 ng de ADN purificado.

- Se añadieron $5 \mu 1$ de primers quedando a una concentración final de $0,1 \mu \mathrm{M}$, para un volumen final de $30 \mu \mathrm{l}$. 
- Las condiciones de la PCR fueron 45 ciclos con el siguiente programa: $95^{\circ}$ durante 30 segundos, seguidos de 30 segundos a $64^{\circ} \mathrm{y}$ 30 segundos a $72^{\circ}$.

Al producto final de la PCR se midió la concentración de ADN en espectrofotómetro y se analizaron $5 \mu \mathrm{l}$ en un gel de agarosa para comprobar la correcta amplificación y pureza del fragmento de PCR. Finalmente se congeló a $-20^{\circ}$ hasta su procesamiento para la secuenciación.

\subsection{SECUENCIACIÓN DE LOS EXONES}

La secuenciación se realizó mediante el procedimiento de secuenciación cíclica con BigDyeTerminator v3.1 y electroforesis multicapilar automático (3130XL GeneticAnalyzer). Los datos se analizaron mediante el programa Sequence scanner v 1.0 y 7 o Chromas lite.

La reacción de secuenciación requiere un ADN muy puro. Previa a la secuenciación se purificaron los productos de pcr en minicolumnas de Wizard ${ }^{\circledR}$ SV Gel and PCR Clean-Up System, siguiendo los pasos indicados por el fabricante:

Mezclar igual volumen de Membrane Binding Solution con el producto PCR, introducir en la minicolumna e incubar 1 min. Centrifugar a 16000 x g 1 min, eliminar liquido eluído. Añadir 700 de membrane wash solution ( previamente reconstituido con etanol, según indicaciones). Centrifugar $16000 \mathrm{x}$ g 1 min y eliminar liquido eluído. Repetir lavado y centrifugación. Vaciar de nuevo el líquido eluído y centrifugar 1 min con la tapadera de la centrífuga abierta para secar de alcohol residual la minicolumna. colocar la minicolumna en un tubo de $1,5 \mathrm{ml}$ y pipetear $50 \mu \mathrm{l}$ de $\mathrm{H} 2 \mathrm{O}$ libre de nucleasas. Incubar $1 \mathrm{~min}$ y centrifugar otro min a $16000 \mathrm{x}$ g. El eluído contiene el ADN purificado.

Tras esto preparamos la reacción de secuenciación. Se hicieron reacciones de secuenciación para la cadena sense y otra de la cadena antisense, empleando para cada reacción su respectivo primer (los mismos empleados en la PCR).

Cada reacción de secuenciación incorporaba entre 30-60 ng de ADN genómico, 6,4 picomoles de cebador para un volumen final de $20 \mu 1$.

Las reacciones se realizaron a $50{ }^{\circ} \mathrm{C}$, con excepción de las hechas para los exones 7-9 que se realizaban a $60^{\circ} \mathrm{C}$ porque contiene algunas regiones con un alto contenido de G-C.

\subsection{INTERPRETACIÓN DEL CROMATOGRAMA}

Una vez obtenidos los cromatogramas, en cada uno se compararon la muestra tumoral frente a su tejido "normal" (Figura 5). Los cromatogramas proporcionan "picos" para cada nucleótido, en cada posición. Se consideraron mutaciones cuando había un cambio de nucleótido. En muchos casos el nucleótido presente es doble, es decir había dos tipos de células en la muestra: 
unas mutadas y otras no. En estos casos se evaluó un porcentaje de mutación en función de la altura de cada pico. Obsérvese un caso claro de doble población presente en el tejido tumoral pero no en el normal.

Otras las mutaciones encontradas fueron las delecciones, inserciones, mutaciones sin sentido o stop, neutras y en algunos casos mutaciones regiones intrónicas cercanas al exón que pudieran estar implicadas en un splicing erróneo.

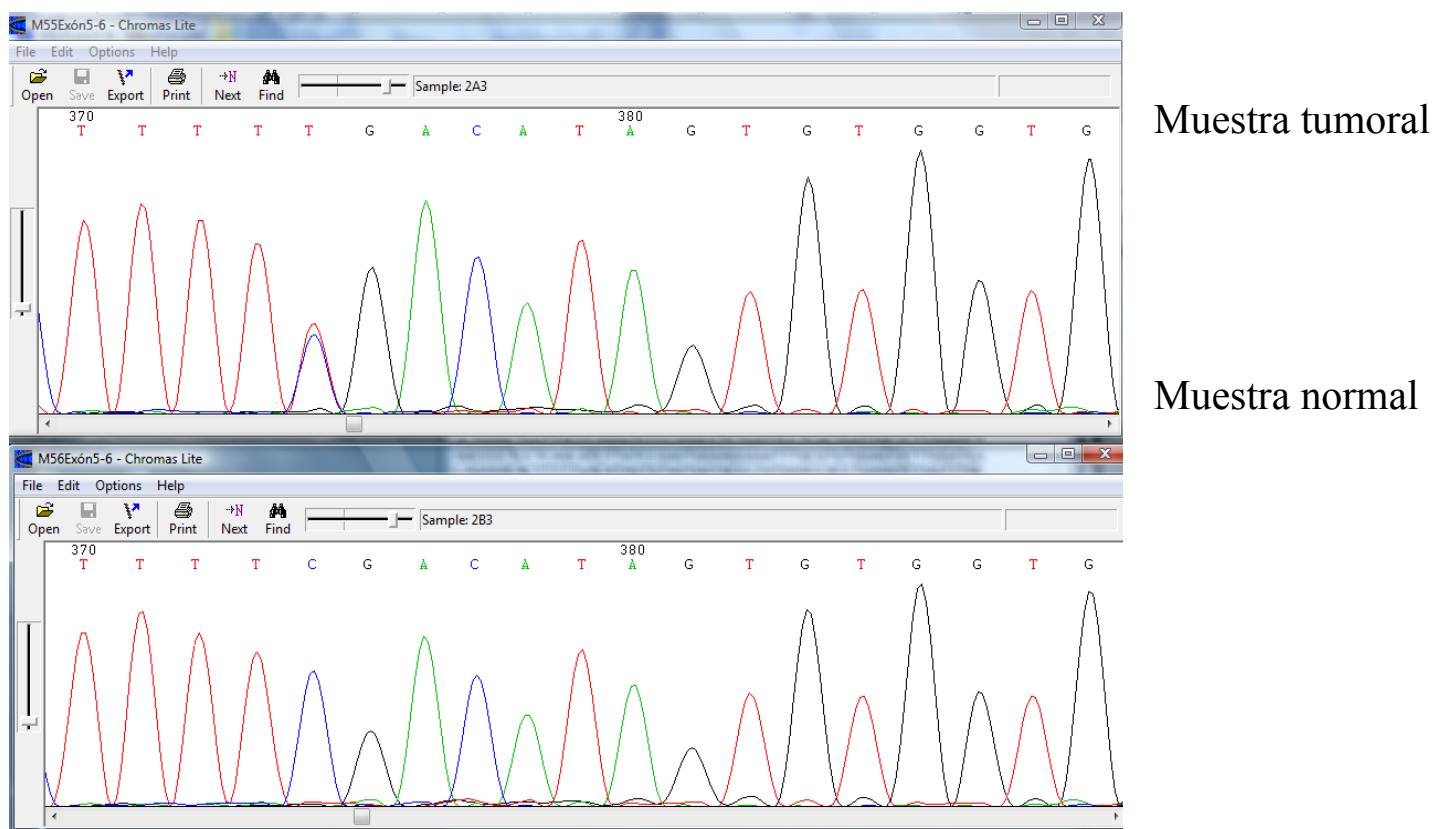

Figura 5. Cromatograma obtenido mediante secuenciación de muestra tumoral y normal.

\section{Análisis estadístico}

La comparación de los niveles de mARN entre las muestras de mucosa normal y tejido tumoral de paciente se hizo mediante el test de T de Student. Los resultados del análisis de correlación se han expresado por el cociente de correlación de Pearson. Valores de P menores de 0.05 se consideraron significativos. 


\section{RESULTADOS}

\section{Caracterización de las mutaciones en el gen TP53}

Se ha secuenciado el ADN de las muestras tumoral y normal de 177 pacientes. Hemos encontrado mutaciones en el gen TP53 en el $49.7 \%$ de los casos analizados (88/177), todas ellas en la zona de unión al DNA (Figura 6A); de ellas el 79.1\% corresponde a mutaciones del tipo missense (Figura 6B). Ningún tumor presentó más de una mutación missense. Tres tumores presentaron mutaciones intrónicas y missense al mismo tiempo. Estos tumores se categorizaron como mutaciones missense (Warren y cols., 2013). Nueve tumores presentaron mutaciones intrónicas, 12 nonsense, 2 silenciosas y 3 deleciones. Las mutaciones silenciosas e intrónicas se han clasificado como mutaciones ya que pueden alterar el splicing de la proteína o la estabilidad del ARN (Soussi y cols., 2006).

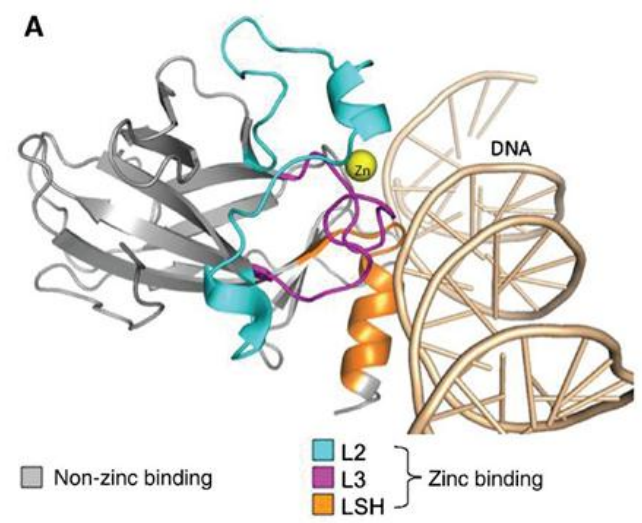

B

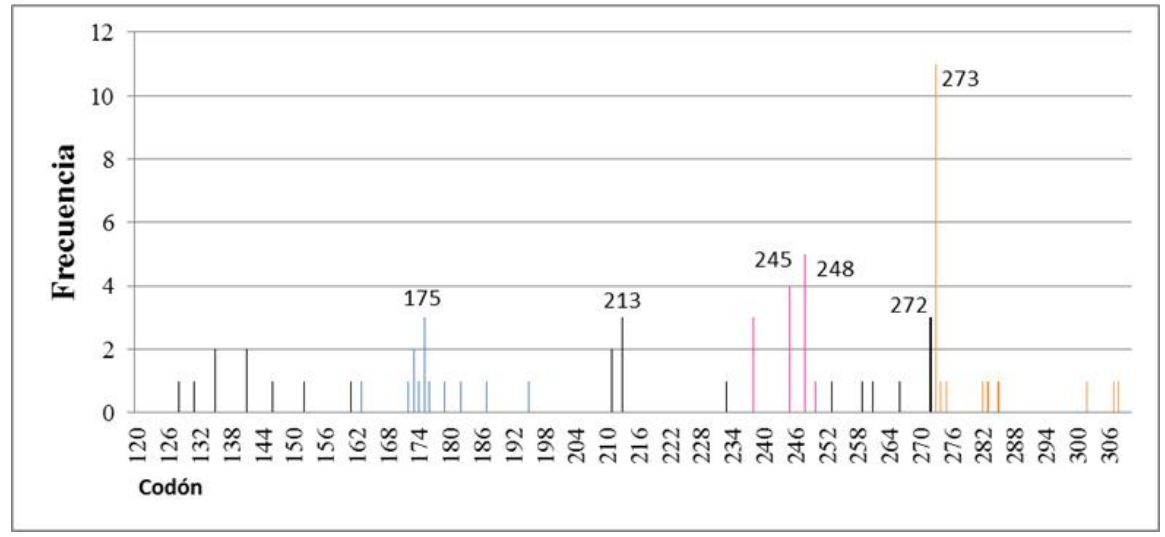

Figura 6. A, structure of the p53 DNA-binding domain. The ZB regions are cyan for L2, magenta for L3, and orange for LSH; non-NZBs are gray; the zinc atom $(\mathrm{Zn})$ is yellow. Image was rendered using PyMOL 1.4.1 software and p53 crystal structure PDB ID: 1TSR. B, missense mutations in the DNAbinding domain. Codons encompassing ZB mutations are denoted by colored horizontal bars spanning L2 (codons 163-195), L3 (codons 236-251), and LSH (codons 273-286); NZB mutations are denoted by gray bars. Codon numbers are provided for hotspots. 


\section{Relación del estatus del gen TP53 con la expresión de los genes NAT, ASMT, MT1, MT2 Y ROR $\alpha$}

La expresión del mARN de los genes de señalización y síntesis de melatonina se determinó en las muestras tumorales y su correspondiente normal de 177 pacientes de cáncer colorrectal. En el caso de los genes de síntesis, es decir AA-NAT y ASMT, se encontraron diferencias significativas en la expresión de AA-NAT entre muestra normal y tumoral de los pacientes considerando el total de los casos analizados (TC), lo que está de acuerdo con otros resultados ya publicados (León y cols., 2014). Cuando categorizamos las muestras según el estatus del gen TP53 (mutado o no mutado), encontramos que aparecen diferencias en la expresión del mARN de AA-NAT entre muestras normales y tumorales, pero únicamente en el caso de los tumores en los que p53 está mutado (Figura 7A). La expresión de ASMT no cambia cuando comparamos las muestras normales con las tumorales ni en el total de casos, ni cuando categorizamos las muestras según el estatus de p53 (Figura 7B).
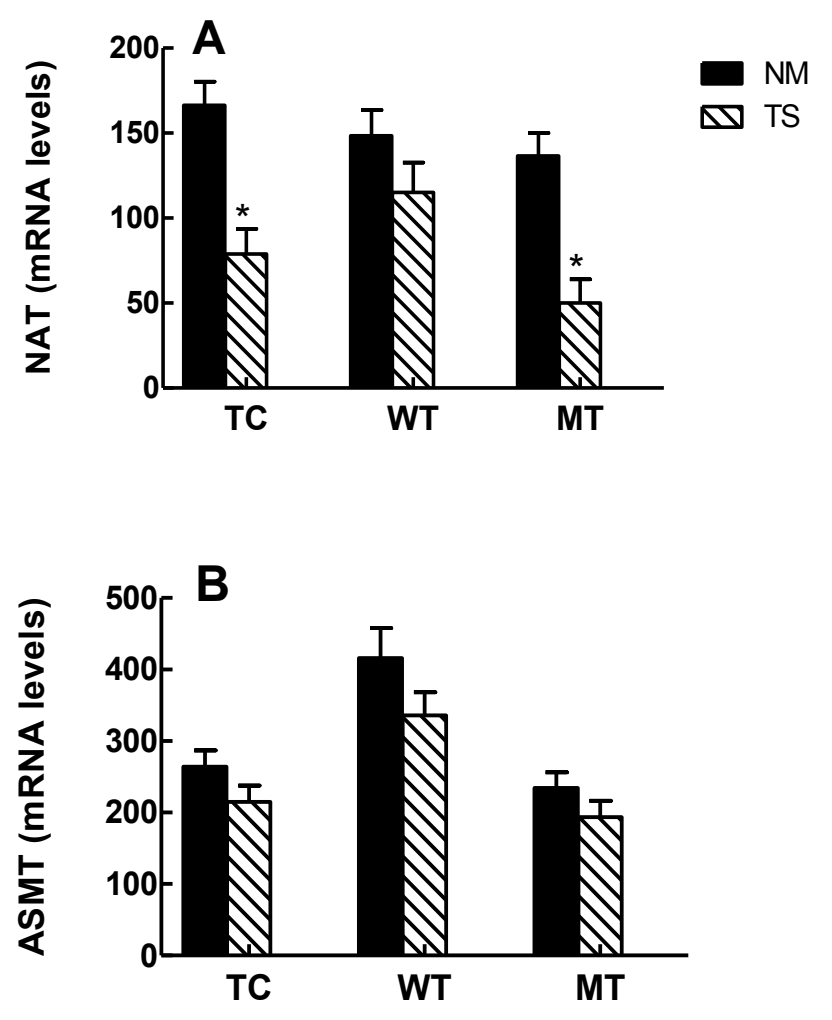

Figura 7. Cambio relativo de la expresión de los niveles del mARN de AA-NAT y ASMT en el total de casos analizados (TC), en los tumores no mutados en p53 (WT) y en los tumores mutados (MT). Los datos representan las media $\pm \mathrm{DE}$ de los casos. * $\mathrm{P}<0.001$ vs NM. 
La expresión del mARN de MT1 y MT2 (Figura 8A y 8B) cambia cuando se comparan las muestras tumorales con sus correspondientes muestras pareadas, en el total de casos, mientras que la expresión del mARN de RORa, no cambia (Figura 8C). Estos resultados están de acuerdo con otros previamente publicados (León y cols., 2012). La expresión de MT1 no depende de que p53 se encuentre o no mutado (Figura A), mientras que la expresión de MT2 es menor en muestra tumoral frente a muestra normal únicamente en el caso de tumores mutados en el gen p53 (Figura 8B), igual que ocurre con NAT. La expresión tumoral de ROR $\alpha$ cambia con respecto a la expresión en muestras normales cuando tenemos en cuenta el estatus de p53 (Figura 8C).
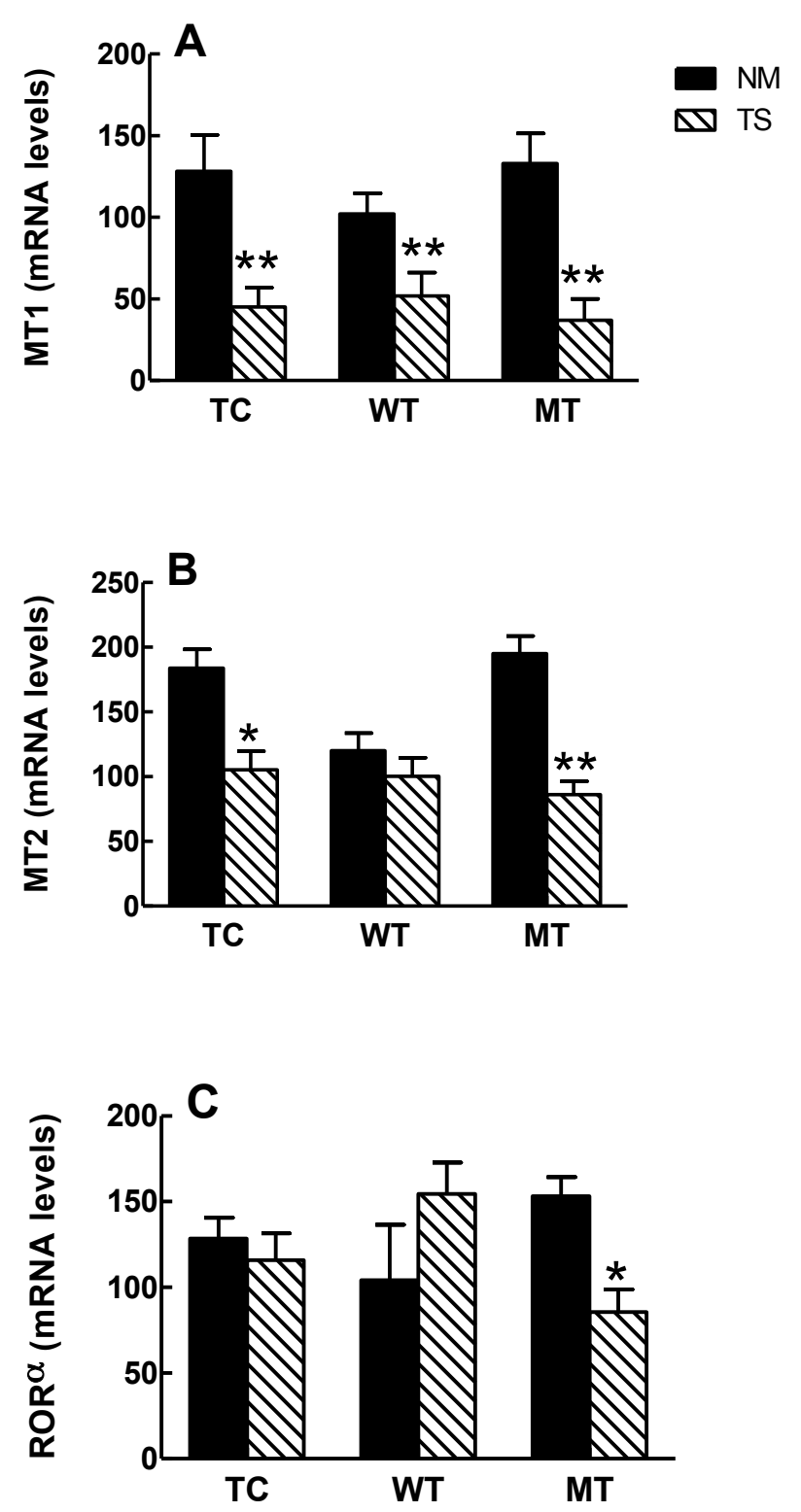

Figura 8. Cambio relativo de la expresión de los niveles del mARN de MT1, MT2 y ROR en el total de casos analizados (TC), en los tumores no mutados en p53 (WT) y en los tumores mutados (MT). Los datos representan las media $\pm \mathrm{DE}$ de los casos. * $\mathrm{P}<0.01$ vs NM; ** $\mathrm{P}<0.001$ vs NM. 


\section{Análisis de la expresión de NAT, ASMT, MT1, MT2 Y RORa en lineas celulares establecidas de cáncer de colon.}

Hemos analizado la expresión de los genes de síntesis y señalización de melatonina en líneas establecidas de cáncer de colon con diferente estatus de del gen TP53. Tal y como se describe en la sección de Materiales y Métodos, se han utilizado cuatro líneas celulares establecidas de cáncer de colon: RKO y HCT-116, con el p53 salvaje, y HT-29 y DLD-1, con el p53 mutado. Como puede verse en la figura 9, existe una gran diferencia de expresión de MT2 y AA-NAT entre las líneas RKO y HCT-116 y las líneas HT-29 y DLD-1. Aunque también se han encontrado algunas diferencias en la expresión de MT1, no está tan clara, en este caso, la separación entre p53 mutado y no mutado. No se ha determinado la expresión de ASMT y ROR $\alpha$.

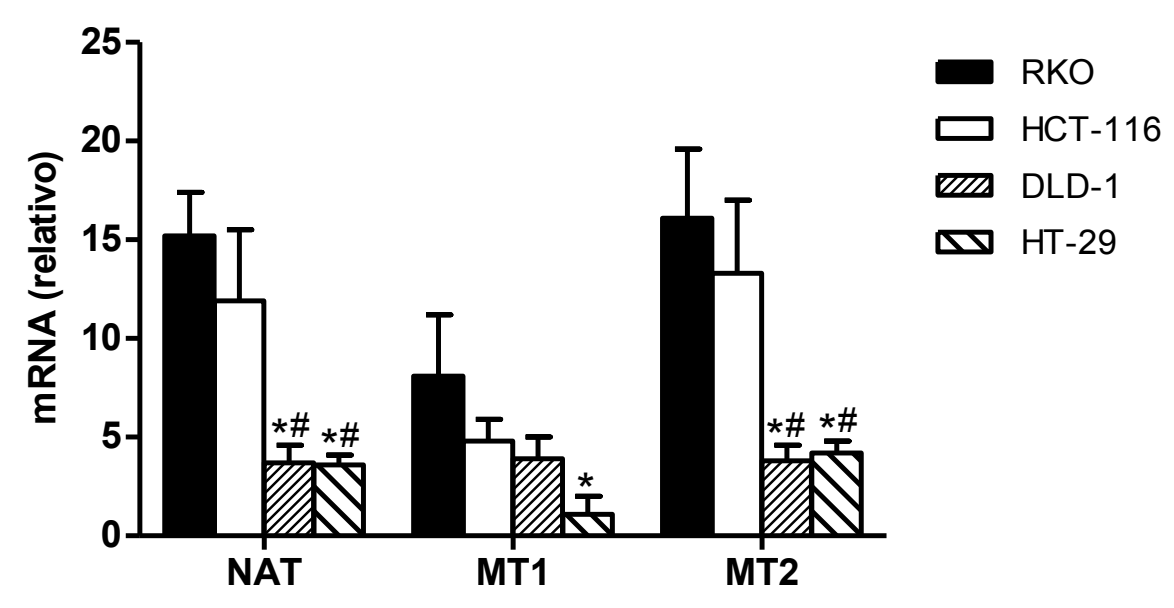

Figura 9. Expresión del mARN de MT1, MT2 y NAT en líneas celulares establecidas de cáncer colorrectal. Cada experimento representa la media \pm E.E.M de tres experimentos realizados por duplicado. $* \mathrm{P}<0.001$ vs $\mathrm{RKO}$; $\# \mathrm{P}<0.001$ vs $\mathrm{HCT}-116$. 


\section{DISCUSIÓN}

Aunque la relación de la melatonina con el crecimiento y la extensión del cáncer se conoce desde hace más de 80 años, no fue hasta 1977 cuando se establecieron las bases científicas de esa relación. Desde entonces numerosos estudios han sugerido la asociación de bajos niveles de melatonina con la progresión de varios cánceres, entre ellos el CCR (Mediavilla y cols., 2010; Jung y Ahmad, 2006).

En nuestro estudio hemos analizado la expresión del mARN de los genes de síntesis de melatonina, AA-NAT y ASMT en muestras tumorales de pacientes con CCR en comparación con sus correspondientes normales. Nuestros resultados muestran un descenso en la expresión de AA-NAT, enzima limitante en la síntesis de melatonina, en las muestras tumorales con respecto a sus pareadas normales en el total de pacientes con CCR, mientras que en el caso de ASMT no hemos encontrado diferencias. Hallazgos similares se pueden encontrar en un estudio previo, aunque en este caso el número de muestras analizadas es menor (León y cols, 2014). Esto está en contradicción con otro estudio, en el que se encuentran niveles similares de melatonina en normales y tumorales de pacientes con CCR, aunque en este caso el número de pacientes analizados fue únicamente de 19 (Vician y cols., 1999). Otros autores han encontrado un descenso de la expresión de ambos enzimas, AA-NAT y ASMT, y de la secreción de melatonina en biopsias de pacientes con colangiocarcinoma (Han y cols., 2011).

En este estudio hemos analizado la expresión del mARN de los receptores de membrana de melatonina, MT1 y MT2, y nuclear, ROR $\alpha$, entre muestras tumorales y sus correspondientes normales. La expresión tanto de MT1 como de MT2 es menor en muestras tumorales que en muestras normales, en el total de casos, mientras que la expresión de RORa no varía. Estos resultados ya se han descrito en estudios previos (León y cols., 2012). En contraste con nuestros resultados, otros trabajos muestran aumento de los niveles de MT1 en muestras de cáncer de mama. Este trabajo muestra un aumento de MT1 en muestras de carcinomas ductales invasivos, comparados con muestras de enfermedad fibroquística (Jablonska y cols., 2013). También se ha demostrado un aumento de la expresión de MT2 en muestras de cáncer gástrico en comparación con muestras procedentes de individuos sanos, aunque no se ha encontrado ninguna relación con la progresión del tumor (Nasrabadi y cols., 2014).

El análisis de las mutaciones del gen TP53 ha puesto de manifiesto que existen diferencias en la expresión de AA-NAT entre las muestras normal y tumoral, pero sólo en el caso de los tumores con mutaciones en p53. ASMT, al igual que en el total de casos, no cambia cuando clasificamos la muestra según p53. No hemos encontrado estudios similares que comparen la expresión de los genes de síntesis 2 de melatonina y el estatus de p53. La expresión de MT1 no depende del estado mutado o no mutado de p53, ya que en ambos tipos de muestras se observa un descenso de la expresión de este receptor. No ocurre lo mismo en el caso de MT2, el cual disminuye su expresión en 
muestras tumorales con respecto a las normales pero únicamente en el caso de tumores mutados. Resulta llamativo el resultado obtenido con respecto a la expresión de ROR $\alpha$, que aunque no cambia en muestras tumorales con respecto a las normales en el total de casos analizados, desciende en los tumores mutados.

Hemos analizado la expresión de AA-NAT, MT1 y MT2 en cuatro líneas celulares de cáncer colorrectal, dos de ellas con p53 salvaje (RKO y HCT-116) y dos con p53 mutado (HT-29 y DLD-1). Las observaciones en líneas celulares concuerdan con nuestros resultados en muestras de pacientes, existiendo una gran disminución de la expresión de AA-NAT y MT2 en las líneas que presentan mutación en p53 con respecto a las que no. No hemos encontrado diferencias tan grandes en el caso de MT1. No hemos determinado la expresión de ASMT y ROR $\alpha$.

Según el modelo tradicional de carcinogénesis, el desarrollo del CCR se lleva a cabo en múltiples pasos, debido a la acumulación de alteraciones genéticas discretas, cada una de las cuales proporciona una ventaja selectiva en el crecimiento de las células tumorales (Fearon y Volgelstein, 1990). Dado lo sugerido acerca de la acción de la melatonina en el bloqueo del desarrollo y crecimiento tumoral y la implicación de los receptores de la melatonina en la actividad anticancerosa de esta indolamina, un descenso en la síntesis y señalización de la misma puede representar una defíciencia en los mecanismo protectores y por lo tanto una mayor susceptibilidad hacia desarrollo de tumores (Jung y Ahmad, 2006). Las mutaciones en el gen p53 aparecen en más del 50\% de los tumores de colon que se desarrollan. En el caso del CCR esporádico, las mutaciones en este gen suelen aparecer como un paso previo al desarrollo de adenocarcinomas (Worhley y cols., 2007).

En nuestro estudio demostramos una relación entre estatus p53 y la expresión de genes relacionados con síntesis y señalización de melatonina, pero no podemos saber que evento ocurre antes. Según Santoro y cols, la activación de la reparación del ADN dependiente de p53 está mediada por MT1 y MT2, y por lo tanto la ausencia de estos receptores provoca una disfunción en la habilidad de la melatonina para reducir tanto la proliferación celular como el potencial clonogénico de las células tumorales (Santoro y cols., 2013). De la misma manera que se ha descrito para otros genes relacionados con el cáncer, puede ocurrir que AA-NAT, MT2 y ROR $\alpha$ sean genes diana de p53, pero para poder demostrarlo, son necesarios otro tipo de experimentos como el conocido CHIP assay. Otra posibilidad es la regulación por p53 a través de miRNAs, ya que se ha demostrado que estos últimos son los efectores en el final de la cáscada de señalización de p53 (Li y cols., 2014). Por ejemplo, se ha demostrado que miR-483 regula la síntesis de melatonina controlando AA-NAT en la glándula pineal (Clokie y cols., 2012).

En conclusión, en este trabajo hemos demostrado que existe una relación entre la expresión de AA-NAT, MT2 y ROR $\alpha$ y el estado mutado o no mutado del gen p53 en nuestra cohorte de pacientes de CCR y en líneas establecidas de cáncer colorrectal. 


\section{REFERENCIAS}

1. Acuña-Castroviejo D, Escames G, Venegas C, Díaz-Casado ME, LimaCabello E, López LC, Rosales-Corral S, Tan DX, Reiter RJ. (2014). Extrapineal melatonin: sourses, regulation, and potential functions. Cell. Mol. Life Sci. Feb 20.

2. Ahmad R, Haldar C (2010). Melatonin and androgen receptor expression interplay modulates cell-mediated immunity in tropical rodent Funambulus pennant: an in-vivo and in-vitro study. Scand J Immunol, 71: 420-30.

3. Anisimow VN, Popovich IG, Shtylik AV, Zabezhinski MA, Ben-Huh H, Gurevich P. (2000). Melatonin and colon carcinogenesis. III. Effect of melatonin on proliferative activity and apoptosis in colon mucosa and colon tumors induced by 1,2-dimethylhydrazine in rats. Exp Toxicol Pathol, 52: 71-76.

4. Arendt J, Middleton B, Williams P, Francis G, Luke C. (2006). Sleep and circadian phase in a ship's crew. J Biol Rhythms, 21: 214-21.

5. Axelrod J (1978). Introductory remarks on regulation of pineal indoleamine synthesis. (Chairman's introduction). J Neural Transm Suppl, 13: 73-9.

6. Becker-Andre M, Wiesenberg I, Schaeren-Wiemers N, Andre E, Missbach M, Saurat JH, Carlberg C (1994). Pineal gland hormone melatonin binds and activates an orphan of the nuclear receptor superfamily. J Biol Chem 269: 28531-28534.

7. Benitez-King G, Huerto-Delgadillo L, Anton-Tay F (1993) Binding of 3Hmelatonin to calmodulin. Life Sci 53:201-207.

8. Bogaert J, Prenen H (2014) Molecular genetics of colorectal cancer. Ann Gastroenterol, 27: 9-14

9. Bonis PA, Trikalinos TA, Chung M, Chew P, Ip S, DeVine DA, Lau J. (2007). Hereditary nonpolyposis colorectal cáncer: diagnostic strategies and their implications. Evid Rep Technol Assess (Full Rep). 150: 1-180

10. Brady CA, Attardi LD. (2010). P53 at a glance. Journal of Cell Science. 123, 2527- 2532

11. Brooks CL, Gu W. (2006) p53 ubiquitination: Mdm2 and beyond. Mol Cell, 21: 307-15

12. Brydon L, Roka F, Petit L, de CP, Tissot M, Barrett P, Morgan PJ, Nanoff C, Strosverg AD, Jockers R (1999). Dual signaling of human Mel 1a 
melatonin receptors via $G$ (i2), $G$ (i3), and $G(q / 11)$ proteins. Mol Endocrinol 13: 2025-2038.

13. Bubenik GA (2008). Thirty four years since the discoverty of gastrointestinal melatonin. Journal of physiology and pharmacology 59: $33-51$.

14. Bubenik GA (1980). Localization of melatonin in the digestive tract of the rat. Effect of maturation, diurnal variation, melatonin treatment and pinealectomy. Horm Res, 12: 313-323.

15. Bubenik GA, Brown GM. (1997). Pinealectomy reduces melatonin levels in the serum but no in the gastrointestinal tract of the rat. Biol Signals, 6: 40-44.

16. Bubenik Ga, Hacker RR, Brown GM , Bartos L. (1999) Melatonin concentration in luminal fluid, mucosa and muscularis of the bovine and porcine gastrointestinal tract. J Pineal Res, 26: 56-63

17. Bullock AN, Henckel J, DeDecker BS, Johnson CM, Nikolova PV, Proctor MR, Lane DP and Fersht AR (1997). Thermodynamic stability of wild- type and mutant p53 core domain. Proc. Natl. Acad. Sci. USA 94: 14338- 14342

18. Bullock AN, Henckel J and Fersht AR (2000). Quantitative analysis of residual folding and DNA binding in mutant p53 core domain definition of mutant states for rescue in cancer therapy. Oncogene 19: 1245- 1256

19. Cadwell, C. and Zambeti, G.P. (2001) The effects of wild-type p53 tumor suppressor activity and mutant p53 gain-of-function on cell growth. Gene 277,15-30.

20. Cao, Z., Song, J. H., Park, Y. K., Maeng, E. J., Nam, S. W., Lee, J. Y. and Park, W. S. (2009) The p53 codon 72 polymorphism and susceptibility to colorectal cancer in Korean patients. Neoplasma, 56, 114-118

21. Castagnetta LA, Granata OM, Traina A, Ravazzolo B, Amoroso M, Miele M, Bellavia V, Agostara B, Carruba G (2002). Tissue content of hydroxyestrogens in relation to survival of breast cáncer patients. Clin Cancer Res, 8: 3146-55.

22. Center, M. M., Jemal, A., Smith, R. A. and Ward, E. (2009). Worldwide variation in colorectal cancer. CA Cancer J. Clin., 59, 366- 378.

23. Chen CQ ${ }^{1}$, Fichna J, Bashashati M, Li YY, Storr M (2011). Distribution, function and physiological role of melatonin in the lower gut. World $\mathrm{J}$ Gastroenterol, 17: 2888-98.

24. Chow PH, Lee PPN, Poon AMS, Shiu SYW, Pang SF. (1997). The gastrointestinal system: A site of melatonin paracrine action. IN: 
melatonin: a universal photoperiodic signal with diverse action (Tang PL, Pang SF, Reiter RJ, eds.), Basel Switzerland, Karger, pp 123-132.

25. Clemens JW ${ }^{1}$, Jarzynka MJ, Witt-Enderby PA. (2001). Down-regulation of $\mathrm{mt} 1 \mathrm{melatonin}$ receptors in rat ovary following estrogen exposure. Life Sci, 69: 27-35.

26. Clokie SJ1, Lau P, Kim HH, Coon SL, Klein DC. (2012) MicroRNAs in the pineal gland: miR-483 regulates melatonin synthesis by targeting arylalkylamine $\mathrm{N}$-acetyltransferase, J Biol Chem, 287: 25312-24

27. Dakouras, A., Nikiteas, N., Papadakis, E. et al. (2008) P53Arg72 homozygosity and tis increased incidence in left-sided sporadic colorectal adenocarcinomas, in a Greek-Caucasian population. Anticancer Res., 28, 1039-1043.

28. Dalio MB, Haikel Júnior LF, Dalio RB, Pinto AP, Silva JC, Vespúcio MV, Guimarães MA, Garcia SB (2006). A study of the effects of pinealectomy on intestinal cell proliferation in infant newborn rats. Acta Cir Bras, 21: 16-20.

29. DeLeo, A.B., Jay, G., Appella, E., Dubois, G.C., Law, L.W. and Old, L.J. (1979) Detection of a transformation-related antigen in chemically induced sarcomas and other transformed cells of the mouse. Proc. Natl. Acad. Sci. USA 76, 2420-2424.

30. Douglas K. Rex, MD, FACG, David A. Johnson, MD, FACG, Joseph C. Anderson, MD, Phillip S. Schoenfeld, MD, MSEd, MSc (Epi), FACG, Carol A. Burke, MD, FACG and John M. Inadomi, MD, FACG. (2009). American College of Gastroenterology Guidelines for Colorectal Cancer Screening 2008. Am J Gastroenterol. 104: 739- 750

31. Dubocovich ML, Markowska M (2005). Functional MT1 and MT2 melatonin receptors in mammals. Endocrine 27: 101-110.

32. Eliyahu, D., Michalovitz, D. and Oren, M. (1985) Overproduction of p53 antigen makes established cells highly tumorigenic. Nature 316, 158-160.

33. Fearon ER. (2011). Molecular genetics of colorectal cancer. Annu Rev Pathol. 6:479-507

34. Fearon, E. R. and Vogelstein, B. (1990). A genetic model for colorectal tumorigenesis. Cell, 61, 759- 767

35. Gamper, A.M and Roeder, R. G (2008). Multivalent binding of $\mathrm{p} 53$ to the STAGA complex mediates coactivator recruitment after UV damage. Mol. Cell. Biol. 28, 2517- 2527

36. Gemignani, F., Moreno, V., Landi, S. et al. (2004) A TP53 polymorphism is associated with increased risk of colorectal cancer and with reduced levels of TP53 mRNA. Oncogene, 23, 1954-1956. 
37. Guerrero JM, Pozo D, Diaz-Rodriguez JL, Martinez-Cruz F, Vela-Campos F. (2006). Impairment of the melatonin rhythm in children with Sanfilippo syndrome. J Pineal Res, 40: 192-3.

38. Halligan S, Wooldrage K, Dadswell E, Kralj-Hans I, von Wagner C, Edwards R, Yao G, Kay C, Burling D, Faiz O, Teare J, Lilford RJ, Morton D, Wardle J, Atkin W, SIGGAR investigators. (2013). Computed tomographic colonography versus barium enema for diagnosis of colorectal cancer or large polyps in symptomatic patients (SIGGAR): a multicentre randomised trial. Lancet. 381: 1185

39. Hamilton W, Round A, Sharp D, Peters TJ. (2005). Clinical features of colorectal cancer before diagnosis: a population- based case- control study. Br J Cancer. 93: 399-405

40. Han Y, Demorrow S, Invernizzi P, Jing Q, Glaser S, Renzi A, Meng F, Venter J, Bernuzzi F, White M, Francis H, Lleo A, Marzioni M, Onori P, Alvaro D, Torzilli G,Gaudio E, Alpini G. (2011). Melatonin exerts by an autocrine loop antiproliferative effects in cholangiocarcinoma: its synthesis is reduced favoring cholangiocarcinoma growth. Am J Physiol Gastrointest Liver Physiol, 301: G623-33

41. He, L., He, X., Lim, L.P., de Stanchina, E., Xuan, Z., Ligang, Y., Xue, W., Zender, L., Magnus, J., Ridzon, D., Jackson, A.L., Linsley, P.S., Chen, C., Lowe. S.W., Cleary, M.A. and Hannon, G.J. (2007). A microRNA component of the p53 tumour suppressor network. Nature 447, 11301134.

42. Heiss G, Wallace R, Anderson GL, Aragaki A, Beresford SA, Brzyski R, Chlebowski RT, Gass M, LaCroix A, Manson JE, Prentice RL, Rossouw J, Stefanick ML; WHI Investigators. (2008). Health risks and benefits 3 years after stopping randomized treatment with estrogen and progestin. JAMA. 299: 1036-45

43. Hermeking, H. (2009) MiR.34a and p53. Cell Cycle 8, 1308

44. Hong Y, Won J, Lee Y, Lee S, Park K, Chang KT, Hong Y (2014) Melatonin treatment induces interplay of apoptosis, autophagy, and senescence in human colorectal cancer cells. J Pineal Res. 2014 Apr;56(3):264-74. doi: 10.1111/jpi.12119. Epub 2014 Jan 31.

45. Iacopetta, B., Russo, A., Bazan, V. et al. (2006). Functional categories of Tp53 mutation in colorectal cáncer: results of an International Collaborative Study. Ann. Oncol., 17, 842- 847

46. Jasperson KW, Tuohy TM, Neklason DW, Burt RW. 2010. Gastroenterology. 138: 2044-58 
47. Johnson CD, Chen MH, Toledano AY, et al. (2008)Accuracy of CT colonography for detection of large adenomas and cancers. N Engl J Med.;359: $1207-1217$

48. Jones SN, Roe AE, Donehower LA, Bradley A. (1995) Rescue of embryonic lethalily in Mdm2-deficient mice by abscence of p53. Nature, 378: $206-8$

49. Jung B, Ahmad N. (2006) Melatonin in cancer management: Progress and promise. Cancer Res, 66: 9789- 9793

50. Kasinski, A.L. and Slack, F.J. (2001). Epigenetics and genetics. MicroRNAs en route to the clinic: progress in validating and targeting microRNAs for cancer therapy. Nat. Rev. Cancer 11: 849-864.

51. Kenzelmann Broz, D. and Attardi, L. D. (2010). In vivo analysis of p53 tumor suppressor function using genetically engineered mouse models. Carcinogenesis. Epub ahead of print PMID: 20097732

52. Kos-Kudla B, Ostrowska Z, Kozlowski A, Marek B, Ciesielska-Kopacz N, Kudla M, Kajdaniuk D, Strzelczyk J, Staszewicz P. (2002). Circadian rhythm of melatonin in patients with colorectal carcinoma. Neuro Endocrinol Lett, 23: 239-42

53. Koushik, A., Tranah, G. J., Ma, J., Stampfer, M. J., Sesso, H. D., Fuchs, C. S., Giovannucci, E. L. and Hunter, D. J. (2006) p53 Arg72Pro polymorphism and risk of colorectal adenoma and cancer. Int. J. Cancer $119,1863-1868$

54. Lal, A., Thomas, M.P., Altschuler, G., Navarro, F., O’Day, E., Li, X.L., Concepcion, C., Han, Y.C., thiery, J., Rajani, D. K., Deutsch, A., Hofmann, O., Ventura, A., Hide, W. and Lieberman, J. (2011). Capture of microRNA- bound mRNAs identifies the tumor supresor miR-34 a as a regulator of growth factor signaling. PLoS Genet. 7, e1002363.

55. Laptenko O and Prives C (2006). Transcriptional regulation by p53: one protein many possibilities. Cell Death Differ. 13, 951- 961

56. Lea, I. A., Jackson, M. A. and Dunnick, J. K. (2009) Genetic pathways to colorectal cancer. Mutat. Res., 670, 96-98

57. Lee BY, Sonnenberg A. (2013) Time trends of mortality from colorectal cáncer in the United States: a birth- cohort analysis. JAMA Intern Med ; 173: 1148

58. León J, Casado J, Jiménez Ruiz SM, Zurita MS, González-Puga C, Rejón JD, Gila A, Muñoz de Rueda P, Pavón EJ, Reiter RJ, Ruiz-Extremera A, Salmerón J. (2014). Melatonin reduces endothelin-1 expression and secretion in colon cancer cells through the inactivation of FoxO-1 and NFк $\beta$. J Pineal Res 56: 415-26 
59. León J, Casado J, Carazo A, Sanjuán L, Maté A, Muñoz de Rueda P, de la Cueva P, Quiles R, Ruiz S, Ruiz-Extremera A, Salmerón J (2012). Gender-Related invasión differences associated with mRNA expression levels of melatonin membrane receptros in colorectal cancer. Molecular carcinogenesis, 51: 608-618.

60. Xiao Ling Li, Matthew F. Jones, Murugan Subramanian, Ashish Lal. (2014). Mutant p53 exerts oncogenic effects through microRNAs and their target gene networks. FEBS Lett Apr12

61. Lodish H, Berk A, Zipursky SL, et al, (2000). MOLECULAR CELL BIOLOGY $4{ }^{\mathrm{TH}}$ EDITION

62. Luchcelli A, Santagostino-Barbone M, Tonini M (1997). Investigation into the contractile response of melatonin in the guinea-pig isolated proximal colon: the role of $5 \mathrm{HT}_{4}$ and melatonin receptors. Br J Pharmacol, 121: $1775-1781$

63. Mammano, E., Belluco, C., Bonafe, M. et al. (2009) Association of p553 polymorphisms and colorectal cancer: modulation of risk and progression. Eur. J. Surg. Oncol., 35, 415-419.

64. Marine JC, Francoz S, Maetens M, Wahl G, Toledo F, Lozano G (2006) Keeping p53 in check:essential and synergistic functions of Mdm2 and Mdm4. Cell Death Differ, 13: 927-34.

65. Mediavilla MD, Sanchez-Barcelo EJ, Tan DX, Manchester L, Reiter RJ. (2010) Basic mechanisms involved in the anti-cancer effects of melatonin. Curr Med Chem.;17(36):4462-81.

66. Mishima K, Okawa M, Shimizu T, Hishikawa Y (2001). Diminshed melatonin secretion in the elderly caused by insufficient environmental illumination. J Clin Endocrinol Metab. 86: 129-34

67. Montes de Oca Luna R, Wagner Ds, Lozano G (1995) Rescue of early embryonic lethalily in mdm2-deficient mice by delection of p53. Nature, 378: 203-6

68. Munro, A. J., Lain, S. and Lane, D.P. (2005) P53 abnormalities and outcomes in colorectal cancer: a systematic review. Br. J. Cancer, 92, 434444.

69. Murphy G, Devessa SS, Cross AS, Inskip PD, Mc Glynn KA, Cook MB. (2011). Sex disparities in colorectal cáncer incidence by anatomic subsite, race and age. Int J Cancer: 128 (12): 1668- 75

70. Naccarati A, Polakova V, Pardini B, Vodickova L, Hemminki K, Kumar R, Vodicka P (2012) Mutations and polymorphisms in TP 53 gene - an overview on the role in colorectal cancer. Mutagenesis. 27: 211-218

71. Nasrabadi NN, Ataee $\quad$ R, Abediankenari S, Shokrzadeh $\quad$ M, Najafi M, Hoseini SV, Jan HH.(2014)Expression of MT2 receptor in patients 
with gastric adenocarcinoma and its relationship with clinicopathological features. J Gastrointest Cancer. 45(1):54-60

72. Nosjean O, Ferro M, Coge F, Beauverger P, Henlin JM, Lefoulon F, Fauchere JL, Delagrange F, Canet E, Boutin JA (2000). Identification of the melatonin- binding site MT3 as the quinine reductase 2. J Biol Chem 275: 31311-31317.

73. Oki, E., Zhao, Y., Yoshida, R., Egashira, A., Ohgaki, K., Morita, M., Kakeji, Y. and Maehara, Y. (2009). The difference in p53 mutations between cancers of the upper and lower gastrointestinal tract. Digestion 79 (Suppl. 1). 33-39

74. Olivier, M., Hollsteins, M. and Hainaut, P. (2010). TP 53 mutations in human cancers: origins, consequences, and clinical use. Cold Sring Harbor Perspect. Biol. 2, a001008

75. Oren, M. and Rotter, V. (2010) Mutant p53 gain-of-function in cancer. Cold Spring Harbor Perspect. Biol. 2, a001107.

76. Perez, L. O., Abba, M. C., Dulout, F. N. and Golijow, C. D. (2006) Evaluation of p53 codon 72 polymorphism in adenocarcinomas of the colon and rectum in La Plata, Argentina. World J. Gastroenterol., 12, 1426-1429.

77. Petit L, Lacroix I, de CP, Strosberg AD, Jockers R (1999). Differential signaling of human Mel 1a and Mel $1 \mathrm{~b}$ melatonin receptors through the cyclic guanosine 3'-5'-monophosphate pathway. Biocherm Pharmacol 58: 633-639.

78. Pietsch, E. C., Humbey, O. and Murphy, M. E. (2006) Polymorphisms in the p53 pathway. Oncogene, 25, 1602-1611

79. Pim, D. and Banks, L. (2004) p53 polymorphic variants at codon 72 exert different effects on cell cycle progression. Int. J. Cancer, 108, 196-199.

80. Quastel R, Rhamimoff R. (1965). Effect of melatonin on spontaneous contraction and response to 5-hydroxytryptamine of rat isolated duodenum. Br J Pharmacol, 24: 455-61.

81. Reiter RJ. (1991). Neuroendocrine effects of light. Int J Biometeorol, 35: $169-75$

82. Reppert SM, Godson C, Mahle CD, Weaver DR, Slaugenhaupt SA, Gusella JF (1995). Molecular characterization of a second melatonin receptor expressed in human retina and brain: the Mel $1 \mathrm{~b}$ melatonin receptor. Proc Natl Acad Sci USA 92: 8734-8538.

83. Risio M.(2010)The natural history of adenomas. Best pract Res Clin Gastroenterol.; 24: 271- 280 
84. Rockey DC, Paulson E, Niedzwiecki D, et al. (2005)Analysis of air contrast barium enema, computed tomographic colonography, and colonoscopy: prospective comparison. Lancet.;365: 305-311

85. Rossouw JE, Anderson GL, Prentice RL, LaCroix AZ, Kooperberg C, Stefanick ML, Jackson RD, Beresford SA, Howard BV, Johnson KC, Kotchen JM, Ockene J; Writing Group for the Women's Health Initiative Investigators. (2002). Risks and benefits of estrogen plus progestin in healthy postmenopausal women: principal results From the Women's Helath Initiative randomized controlled trial. JAMA. 288: 321-33

86. Rothwell PM, Wilson M, Elwin CE, Norrving B, Algra A, Warlow CP, Meade TW. (2010). Long-term effect of aspirin on colorectal cáncer incidence and mortality: 20-year follow-up of five randomised trials. Lancet. 376: 1741-50

87. Russo, A., Bazan, V., Iacopetta, B., Kerr, D., Soussi, T. and Gebbia, N. (2005) The TP53 colorectal cancer international collaborative study on the prognostic and predictive significance of p53 mutation: influence of tumor site, type of mutation, and adjuvant treatment. J. Clin. Oncol., 23, 75187528.

88. Sánchez-Sánchez AM, Martin V, García-Santos G, Rodriguez-Blanco J, Casado-Zapico S, Suarez-Garnacho S, Antolin I, Rodriguez C (2011) Intracellular redox state as determinant for melatonin antiproliferative vs cytotoxic effects in cancer cells. Free Radic Res 45:1333-1341

89. Santoro R, Mori F, Marani M, Grasso G, Cambria AM, Blandino G, Muti $\mathrm{P}$, Strano S (2013). Blockage of melatonin receptors impairs p53-mediated prevention of DNA damage accumulation. Carcinogenesis, 34: 1051-1061.

90. Sameer, A. S., Shah, Z. A., Syeed, N., Banday, M. Z., Bashir, S. M., Bhat, B. A. and Siddiqi, M. A. (2010) TP53 Pro47Ser and Arg72Pro polymorphisms and colorectal cancer predisposition in an ethnic Kashmiri population. Genet. Mol. Res., 9, 651-660

91. Seely D, Wu P, Fritz H, Kennedy DA, Tsui T, Seely AJ, Mills E. (2012) Melatonin as adjuvant cancer care with and without chemotherapy: a systematic review and meta-analysis of randomized trials. Integr Cancer Ther. Dec;11(4):293-303

92. She QB, Chen N, Dong Z (2000). ERKs and p38 kinase phosphorylate p53 protein at serine 15 in response to UV radiation. J Biol Chem, 275: $20444-$ 9

93. Song, H. R., Kweon, S. S., Kim, H. N. et al. (2011) p53 codon 72 polymorphism in patients with gastric and colorectal cancer in a Korean population. Gastric Cancer, 14, 242-247. 
94. Soussi, T. and Beroud, C. (2003) Significance of tp 53 mutations in human cáncer: a critical analysis of mutations at $\mathrm{CpG}$ dinucleotides. Hum Mutat., 21, 192-200

95. Soussi, T. and Lozano, G. (2005) p53 mutation heterogeneity in cancer. Biochem. Biophys. Res. Commun., 331, 834-842.

96. Soussi T, Asselain B, Hamroun D, Kato S, Ishioka C, Claustres M, Béroud C. (2006). Meta-analysis of the p53 mutation database for mutant p53 biological activity reveals a methodologic bias in mutation detection. Clin Cancer Res, 12:62-9

97. Speights VO, Johnson MW, Stoltenberg PH, Rappaport ES, Helbert B, Riggs M. (1991). Colorectal cancer. Current trends in initial clinical manifestations. South Med J. 84: 575-8

98. Stewart Sl, Wike JM, Kato I, Levis DR, Michaud F. A population- based study of colorectal cáncer histology in the United States, 1998-2001Cancer. 2006; 107: 1128- 1141

99. Stehle JH, Saade A, Rawashdeh O, Ackermann K, Jilg A, Sebestény T, Maronde E (2011). A survey of molecular details in the human pineal gland in the light of phylogeny, structure, function and chronobiological diseases. J Pineal Res, 51: 17-43.

100. Surveillance, Epidemiology and End Results (SEER) Program SEER*Stat Database: NAACCR Incidence - CiNA Analytic File, 19952010, for Expanded Races, Custom File With County, ACS Facts and Figures projection Project, North American Association of Central Cancer Registries, 2013

101. Tanaka T, Yasui Y, Tanaka M, Tanaka T, Oyama T, Rahman KM. (2009). Melatonin suppresses AOM/DSS-induced large bowel oncogenesis in rats. Cehm Biol Interact, 177: 128-136.

102. Tomás-Zapico C, Coto-Montes A (2005) A proposed mechanism to explain the stimulatory effect of melatonin on antioxidative enzymes. J Pineal res 39:99-104.

103. Tominaga, T., Iwahashi, M., M., Takifuji, K. et al (2010). Combination of p53 codon 72 polymorphism and inactive p53 mutation predicts chemosensitivity to 5- fluorouracil in colorectal cáncer. Int. J. Cancer, $126,1691-1701$

104. Venegas C, García JA, Doerrier C, Volt H, Escames G, López LC, Retier RJ, Acuña-Castroviejo D (2012) Analysis of the daily changes of melatonin receptors in the rat liver. J Pineal Res. Doi:10.1111/jpi.12019

105. Vician M, Zeman M, Herichova I, Jura ni M, Blazıcek P, Matis P. (1999) Melatonin content in plasma and large intestine of patients with colorectal carcinoma before and after surgery. J Pineal Res, 27:164-169 
106. Vidaurreta, M., Maestro, M. L., Sanz- Casla, M. T., Rafael, S., Veganzones, S., de la Orden, V., Cerdan, J., Arroyo, M. and Torres, A. (2008) Colorectal carcinoma prognosis can be predicted by alteration in gene p53 exons 5 an 8. Int. J. Colorectal Dis., 23, 581- 586

107. Vogelstein, B., Lane, D. and Levine, A.J. (2000). Surfing the p53 network. Natre. 408: 307-210

108. Vousden, K. H. and Prives, C. 2009. Blinded by the light: the growing complexity of p53. Cell 137, 413-431

109. Wade M, Wang YV, Wahl GM (2010) The p53 orchestra: Mdm2 and Mdmx set the tone. Trends Cell Biol, 20: 299-309.

110. Wang G, Kelley RK, (2010) Gappnet. KRAS mutational analysis for colorectal cancer: Application: Pharmacogenomic. PLoS Curr.

111. Warren $\mathrm{RS}^{1}$, Atreya $\quad \mathrm{CE}$, Niedzwiecki $\quad \mathrm{D}$, Weinberg VK, Donner DB, Mayer RJ, Goldberg RM, Compton CC,Zuraek MB, Ye C, Saltz LB, Bertagnolli MM. (2013). Association of TP53 mutational status and gender with survival after adjuvant treatment for stage III colon cancer: results of CALGB 89803. Clin Cancer Rest, 19: 5777-87

112. Weitz J, Koch M, Debus J, Höhler T, Galle PR, Büchler MW. (2005). Colorectal Cancer. Lancet. 365 (9454): 153- 65

113. Whibley, C., Pharoah, P. D. and Hollstein, M. (2009) p53 polymorphisms: cancer implications. Nat. Rev. Cancer, 9, 95-107

114. Wiesenberg I, Missbach M, Carlberg C (1998) The potential role of the transcription factor RZR7ROR as a mediator of nuclear melatonin signaling. Restor Neurol Neurosci 12: 143-150.

115. Winawer SJ, Zauber AG. (2002). The advanced adenoma as the primary target of screening. Gastrointest Endosc Clin N Am. 12: 1-9, v. Review.

116. Worthley, D. L., Whitehall, V. L., Spring, K. J. and Leggett, B. A. (2007) Colorectal carcinogenesis: road maps to cancer. World J. Gastroenterol., 13, 3784- 379

117. Wu YZ, Li B, Wang T, Wang SJ, Zhou YM. (2011). Radiofrecuency ablation vs hepatic resection for solitary colorectal liver metástasis: a meta- analysis. World J Gastroenterol. 17: 4143-8

118. Zhang Y, Lu H (2009) Signaling to p53: ribosomal proteins find ther way. Cancer Cell, 16: 369-77.

119. Zhu, Z. Z., Wang, A. Z., Jia, H. R., Jin, X. X., He, X. L., Hou, L. F. and Zhu, G. (2007) Association of the TP53 codon 72 polymorphism with colorectal cancer in a Chinese population. Jpn. J. Clin. Oncol., 37, 385390 


\title{
ANEXO 1
}

\author{
FORMULARIO DE INFORMACIÓN Y CONSENTIMIENTO INFORMADO \\ ESCRITO. Biobanco del Sistema Sanitario Público de Andalucía \\ NODO: Biobanco del Hospital Universitario San Cecilio
}

\section{DOCUMENTO DE INFORMACIÓN PARA DONACIÓN DE MUESTRAS BIOLÓGICAS AL BIOBANCO PARA INVESTIGACIÓN BIOMÉDICA}

Este documento sirve para que usted otorgue su consentimiento para donar sus muestras biológicas, o las del sujeto al que representa, al Biobanco indicado, establecimiento público, sin ánimo de lucro, dependiente de la Consejería de Salud/del Servicio Andaluz de Salud, que acoge colecciones de muestras biológicas concebidas con fines diagnósticos o de investigación biomédica y organizadas como una unidad técnica con criterios de calidad, orden y destino, donde serán conservadas hasta que se agoten por su uso, salvo que usted solicitara su eliminación. Las muestras biológicas son un excelente elemento para la investigación de enfermedades. A través de dichas investigaciones se podrán obtener datos que permitirán mejorar el conocimiento sobre la aparición, desarrollo y tratamiento de multitud de enfermedades. Esta hoja de información puede contener palabras que usted no entienda. Por favor, pídale al profesional sanitario que le explique la información que no comprenda. Tómese el tiempo necesario para decidir si quiere o no donar su muestra biológica y consulte a personas de su confianza si lo desea. Para consultas que desee plantear posteriormente, podrá dirigirse al Biobanco o a la dirección de correo electrónico: ines.aroca.exts@juntadeandalucia.es / benilde.ayala.exts@juntadeandalucia.es

Las muestras biológicas donadas y sus datos clínicos asociados se utilizarán de conformidad con lo establecido en la Ley 14/2007, de 3 de julio, de Investigación biomédica (en adelante Ley de Investigación biomédica).

Es posible que la información obtenida de las investigaciones en las que se utilicen sus muestras no le genere un beneficio directo, pero habrá contribuido al avance de la medicina y del conocimiento de diversas enfermedades, lo que supondrá, sin duda, un beneficio para la sociedad.

La donación es voluntaria y altruista, por lo que usted no tendrá derecho alguno sobre los resultados que pudieran derivarse de las investigaciones que se lleven a cabo con dichas muestras, de conformidad con la normativa vigente. Su decisión de donar o no, no afectará negativamente a su asistencia sanitaria.

En el apartado dedicado al consentimiento (2.3), podrá decidir si quiere que sus muestras se conserven de forma codificada (en cuyo caso se identifican con un código que protege su identidad) o anonimizada (eliminándose de forma irreversible toda vinculación con su identidad).

Sus muestras y los datos asociados a las mismas sólo se cederán a terceros que las utilicen en investigación biomédica de manera anónima o disociada. $\mathrm{Si}$, por la naturaleza del proyecto de investigación en el que se utilizara su muestra se necesitaran datos clínicos adicionales, el Biobanco coordinaría la obtención de los mismos, siempre que la muestra no hubiera sido anonimizada.

\section{LO QUE USTED DEBE SABER:}

\subsection{Obtención de las muestras}

Las muestras serán obtenidas durante el procedimiento médico-quirúrgico al que va a someterse o se ha sometido durante su proceso asistencial, o a través de un procedimiento 
expreso para obtenerla, según lo indicado en el apartado sobre consentimiento (2.3). En el caso de que usted done las muestras obtenidas durante un procedimiento médico-quirúrgico asistencial, no existe ningún inconveniente adicional derivado de la donación de las mismas. Si, por el contrario, las muestras fueran extraídas expresamente para la donación para investigación biomédica podrían existir inconvenientes vinculados con la obtención de las mismas, de las que será convenientemente informado en la hoja de información del procedimiento correspondiente.

\subsection{Utilización de las muestras}

Usted autoriza a que las muestras donadas sean utilizadas en investigación biomédica, pudiendo establecer restricciones a su utilización.

Las muestras sólo podrán ser utilizadas en proyectos de investigación científicamente avalados, que cumplan las exigencias legales y los principios éticos que rigen la investigación en salud y que sean autorizados por los órganos competentes, de conformidad con lo establecido en la normativa vigente.

Cuando, por razones de salud, usted o su familia lo necesiten, podrán hacer uso de las muestras, siempre que no se hayan agotado o eliminado y no se encuentren anonimizadas.

\subsection{Información relacionada con las muestras}

Si lo solicita, el Biobanco le facilitará la información sobre los proyectos de investigación en los que se utilicen las muestras donadas, si éstas no hubieran sido anonimizadas.

Al donar sus muestras al Biobanco, en este momento puede no saberse el lugar de realización de los análisis. El Biobanco mantiene un registro detallado del lugar de realización de los análisis realizados.

La información que se obtenga puede tener implicaciones para sus familiares, por lo que debe transmitirles dicha información.

\subsection{Posibilidad de ponerse nuevamente en contacto}

Puede que sea necesario ponerse en contacto nuevamente con usted, con el fin de recabar datos o muestras adicionales, o proporcionarle la información relevante para su salud, salvo que haya solicitado que las muestras sean anonimizadas.

\subsection{Protección de datos y confidencialidad de la información}

La información proporcionada en este apartado será aplicable siempre que sus muestras no se encuentren anonimizadas.

Los datos personales recabados serán confidenciales y tratados de acuerdo con la Ley Orgánica 15/1999, de 13 de diciembre, de Protección de Datos de Carácter Personal, y su normativa de desarrollo, y la Ley de Investigación biomédica.

Sus datos de carácter personal serán incorporados a un fichero automatizado, debidamente inscrito en la Agencia Española de Protección de Datos, cuya titularidad corresponde al Servicio Andaluz de Salud. Sólo los responsables del Biobanco podrán identificar a quién corresponde cada muestra o dato, si no está anonimizada.

Podrá ejercer los derechos de acceso, rectificación, oposición y cancelación de sus datos personales, reconocidos en la citada Ley Orgánica 15/19999, con las limitaciones establecidas en dicha Ley. Para ello, deberá dirigirse a la Dirección General de Asistencia Sanitaria del Servicio Andaluz de Salud, Avenida de la Constitución, núm. 18, de Sevilla.

\subsection{Derecho de revocación del consentimiento}


Salvo que sus muestras se encuentren anonimizadas, podrá revocar o retirar, en cualquier momento, el consentimiento prestado.

Para ello, deberá dirigirse al Biobanco, pudiendo solicitar la eliminación o la anonimización de las muestras.

Los efectos de la revocación no se extenderán a los resultados de las investigaciones llevadas a cabo con anterioridad.

\subsection{Información relativa a análisis genéticos}

Salvo que usted manifieste lo contrario en el apartado dedicado al consentimiento, se podrán realizar análisis genéticos. Excepto si sus muestras son anonimizadas, tiene derecho a conocer los datos genéticos que se obtengan a partir del análisis de las muestras donadas, así como de la información relativa a su salud derivada de dichos análisis, según los términos en que exprese su voluntad en el apartado 2.3.

Si no desea recibir dicha información y ésta fuera necesaria para evitar un grave perjuicio para su salud o la de sus familiares biológicos, se informará a un familiar o a un representante. La comunicación se limitará exclusivamente a los datos necesarios para evitar tal perjuicio.

\subsection{Otras consideraciones}

Una vez informado/a de los aspectos relacionados anteriormente en este documento, si decide donar dichas muestras deberá firmar el consentimiento informado para la donación.

CONSENTIMIENTO INFORMADO PARA DONACIÓN DE MUESTRAS BIOLÓGICAS AL BIOBANCO. Biobanco del Sistema Sanitario Público de Andalucía. Nodo del Hospital Universitario San Cecilio.

DATOS DEL/DE LA DONANTE Y DE SU REPRESENTANTE (éste último sólo en caso de incapacidad del/de la donante):

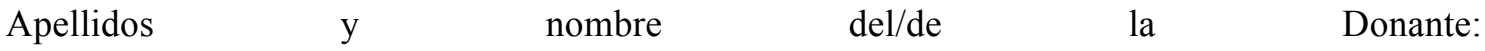

$\mathrm{DNI} / \mathrm{NIE}$

NUHSA:

Apellidos y nombre del/de la representante legal:

$\mathrm{DNI} / \mathrm{NIE}$

PROFESIONALES QUE INTERVIENEN EN EL PROCESO DE INFORMACIÓN Y/O CONSENTIMIENTO:

Los siguientes profesionales declaran que se ha explicado la información relativa a la donación de muestras biológicas al Biobanco:

Apellidos y nombre Fecha Firma

CONSENTIMIENTO:

Yo, D./Dña. declaro bajo $\mathrm{mi}$ responsabilidad que he leído y comprendido el Formulario de Información, del que se me ha entregado un ejemplar. 
He recibido suficiente información sobre la donación de muestras biológicas de................................................. al Biobanco y sobre la posible realización de análisis genéticos sobre las mismas. He podido hacer preguntas sobre la información recibida y hablar con el profesional indicado, quien me ha resuelto todas las dudas que le he planteado.

Dichas muestras son:

- Excedentes del procedimiento médico-quirúrgico asistencia al que va a someterse o se ha sometido

- Tomadas mediante

el procedimiento expreso

Asimismo, consiento el tratamiento de los datos clínicos asociados a las muestras.

Deseo que dichas muestras y los datos clínicos asociados sean tratados de forma:

- Codificada (serán identificadas con un código que protege mi identidad, siendo posible volver a ligarlas conmigo) o

- Anonimizada (no se podrán asociar las muestras conmigo, por haberse eliminado de forma irreversible la vinculación entre las mismas y mi identidad). Deseo establecer restricciones respecto al uso de la muestra, para que no sea utilizada en......

Autorizo que se pueda contactar conmigo posteriormente: - SI - NO

En caso afirmativo, por favor, indique el medio de hacerlo:.

Autorizo recibir información sobre datos genéticos y datos relevantes para mi salud (Si solicita que las muestras sean anonimizadas, no podrá recibir esta información)

Marque lo que proceda: - SI - NO

Sé que puedo revocar, en cualquier momento, el consentimiento otorgado en este documento.

En............, a .....de....... de

EL/LA DONANTE EL/LA REPRESENTANTE LEGAL (sólo en caso de incapacidad del/de la donante)

Fdo.: Fdo.:

REVOCACIÓN DEL CONSENTIMIENTO PARA USO DE MUESTRAS DONADAS:

Yo,D.Dña revoco

el consentimiento informado otorgado en

documento.

.(especificar fecha aproximada y/o procedimiento).

Solicito:

- La eliminación de las muestras donadas

- La anonimización de las mismas

Otras

consideraciones:

En

de de. 
EL/LA DONANTE EL/LA REPRESENTANTE LEGAL (sólo en caso de incapacidad del/de la donante)

Fdo.: Fdo.: 